\title{
Modeling and Analysis of FCM UN TRISO Fuel Using the PARFUME Code
}

Blaise P. Collin

September 2013

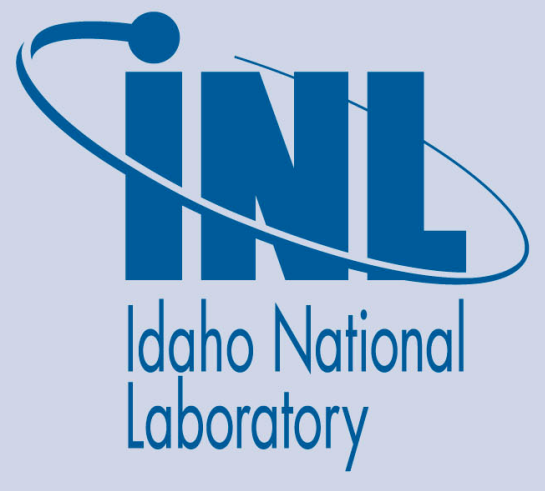

The INL is a U.S. Department of Energy National Laboratory operated by Battelle Energy Alliance. 


\section{DISCLAIMER}

This information was prepared as an account of work sponsored by an agency of the U.S. Government. Neither the U.S. Government nor any agency thereof, nor any of their employees, makes any warranty, expressed or implied, or assumes any legal liability or responsibility for the accuracy, completeness, or usefulness, of any information, apparatus, product, or process disclosed, or represents that its use would not infringe privately owned rights. References herein to any specific commercial product, process, or service by trade name, trade mark, manufacturer, or otherwise, does not necessarily constitute or imply its endorsement, recommendation, or favoring by the U.S. Government or any agency thereof. The views and opinions of authors expressed herein do not necessarily state or reflect those of the U.S. Government or any agency thereof. 
INL/EXT-13-30193

\title{
Modeling and Analysis of FCM UN TRISO Fuel Using the PARFUME Code
}

\author{
Blaise P. Collin
}

September 2013

Idaho National Laboratory

Fuel Performance \& Design

Idaho Falls, Idaho 83415

http://www.inl.gov

Prepared for the

U.S. Department of Energy

Office of Nuclear Energy

Under DOE Idaho Operations Office

Contract DE-AC07-05ID14517 



\section{Modeling and Analysis of FCM UN TRISO Fuel Using the PARFUME Code}

INL/EXT-13-30193

September 2013

Prepared by:

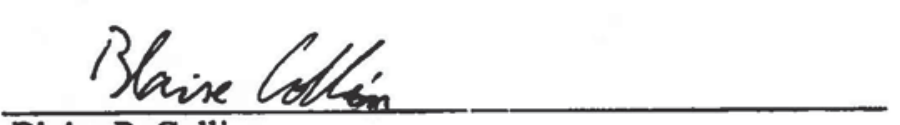

Blaise P. Collin

Reviewed by:

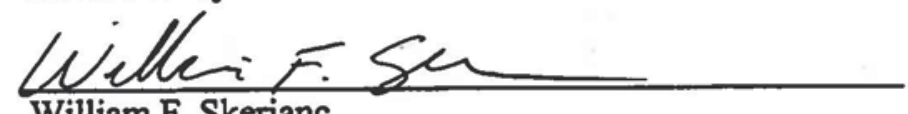

William F. Skerjanc

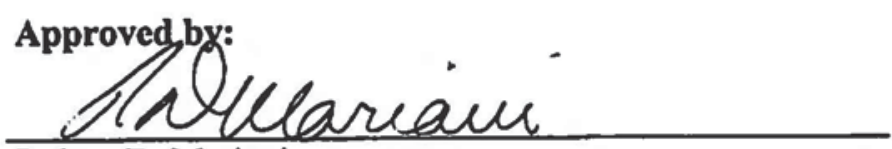

Robert D. Mariani

Fuel Performance \& Design, Marıager

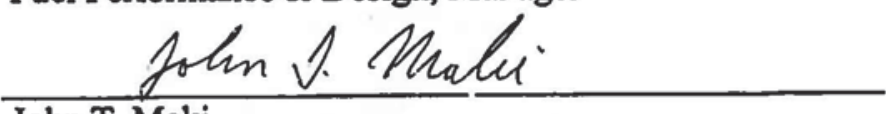

John T. Maki

VHTR Technical Lead, Fuel Performance Modeling
$9 / 25 / 2013$

Date

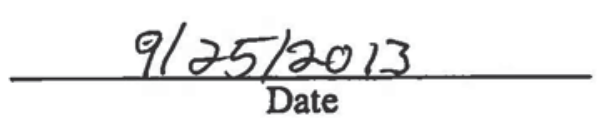

$\frac{9-25-2013}{\text { Date }}$

$9-26-13$ 


\begin{abstract}
The PARFUME (particle fuel model) code was used to assess the overall fuel performance of uranium nitride (UN) tristructural isotropic (TRISO) ceramic fuel in the frame of the design and development of Fully Ceramic Matrix (FCM) fuel.

A specific modeling of a TRISO particle with UN kernel was developed with PARFUME, and its behavior was assessed under irradiation conditions typical of a Light Water Reactor (LWR). The calculations were used to access the dimensional changes of the fuel particle layers and kernel, including the formation of an internal gap. The survivability of the UN TRISO particle was estimated depending on the strain behavior of the constituent materials at high fast fluence and burn-up. For nominal cases, internal gas pressure and representative thermal profiles across the kernel and layers were determined along with stress levels in the pyrolytic carbon (PyC) and silicon carbide ( $\mathrm{SiC})$ layers. These parameters were then used to evaluate fuel particle failure probabilities.

Results of the study show that the survivability of UN TRISO fuel under LWR irradiation conditions might only be guaranteed if the kernel and PyC swelling rates are limited at high fast fluence and burn-up. These material properties have high uncertainty at the irradiation levels expected to be reached by UN TRISO fuel in LWRs. Therefore, more effort is needed to establish material properties, including kernel and $\mathrm{PyC}$ swelling rates, under these conditions before definitive conclusions can be drawn on the behavior of FCM fuel in LWRs.
\end{abstract}




\section{CONTENTS}

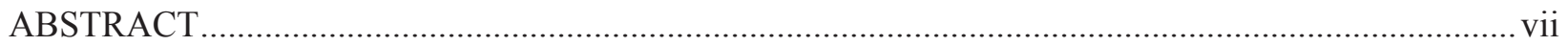

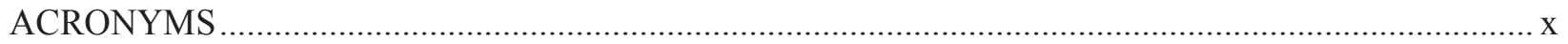

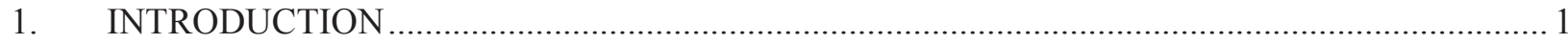

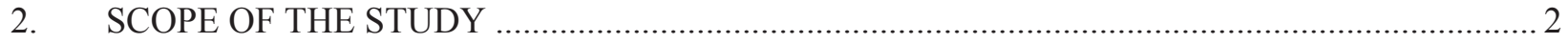

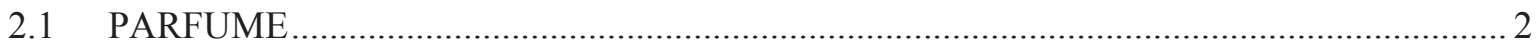

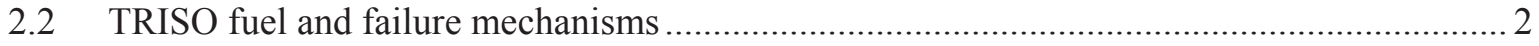

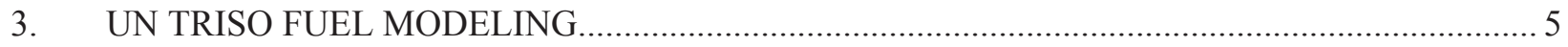

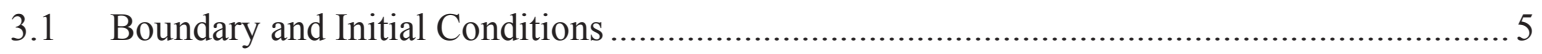

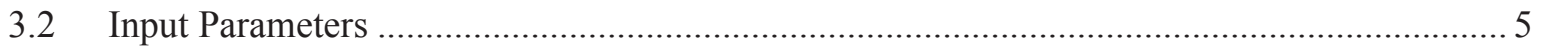

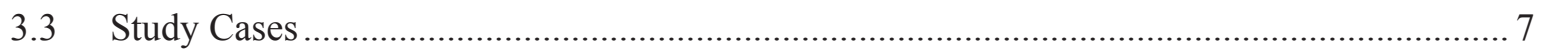

4. RESULTS

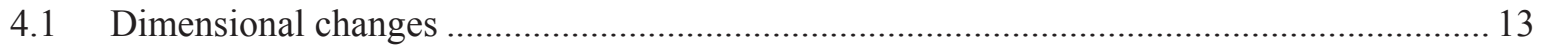

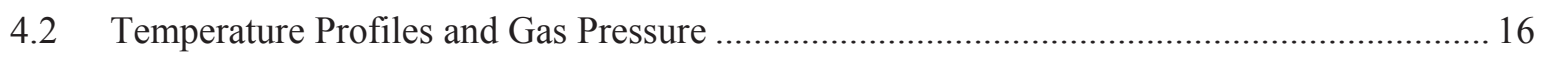

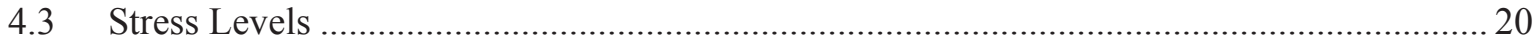

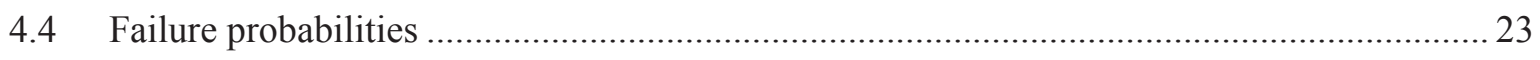

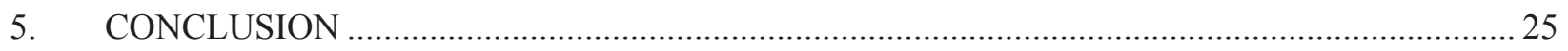

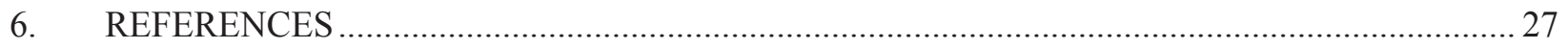

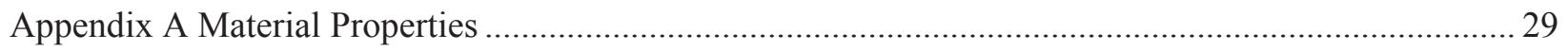

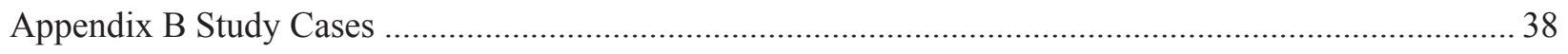

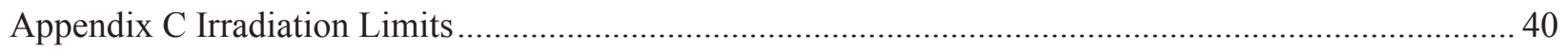

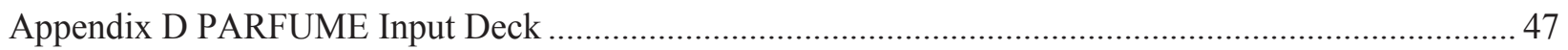




\section{FIGURES}

Figure 1. Maximum achievable fast fluence and burn-up at $850 \mathrm{~K}$ for a kernel swelling rate of $1 \% / \%$ FIMA and "Set 2 " of PyC strain rates.

Figure 2. Dimensional changes of the kernel, buffer, buffer-IPyC gap, and IPyC layer throughout irradiation for nominal case S1_K05_C1.

Figure 3. Kernel swelling and buffer densification throughout irradiation for nominal case S1_K05_C1.

Figure 4. Layer radius variation throughout irradiation for nominal case S1_K05_C1.......................... 14

Figure 5. Layer radius variation throughout irradiation for case S1_K20_C1 ........................................ 16

Figure 6. Kernel, buffer and IPyC temperatures throughout irradiation for nominal case S1_K05_C1.

Figure 7. Temperature profile across the TRISO particle at the end of irradiation for nominal case S1_K05_C1.

Figure 8. Fission gas pressure inside the TRISO particle throughout irradiation for nominal case S1_K05_C1. 18

Figure 9. Fission gas release from the UN kernel throughout irradiation for nominal case S1_K05_C1. 18

Figure 10. Radial stress at the $\mathrm{IPyC} / \mathrm{SiC}$ and $\mathrm{SiC} / \mathrm{OPyC}$ interfaces throughout irradiation for nominal case $\mathrm{S} 1 \mathrm{~K} 05 \mathrm{C} 1$

Figure 11. Tangential stress in $\mathrm{IPyC}, \mathrm{SiC}$ and $\mathrm{OPyC}$ layers throughout irradiation for nominal case S1_K05_C1.....

\section{TABLES}

Table 1. Nominal and boundary irradiation conditions. 5

Table 2. Parameters used in the PARFUME modeling of the UN TRISO fuel .......................................... 6

Table 3. TRISO parameter value ranges used in the UN TRISO study .................................................. 8

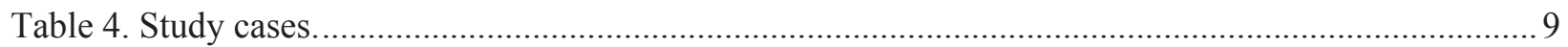

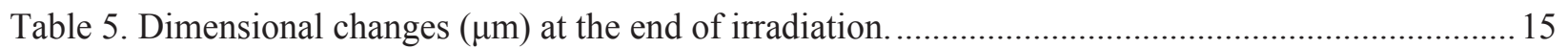

Table 6. Temperatures and fission gas pressure and release fractions at the end of irradiation. ...............20

Table 7. Stress levels in the 3-layer mechanical system at the end of irradiation...................................2 21

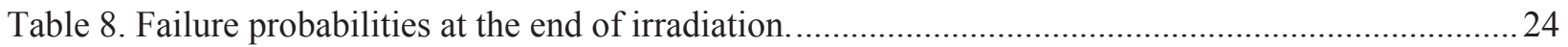




\section{ACRONYMS}

AGR Advanced Gas Reactor

ASME American Society of Mechanical Engineers

BAF Bacon Anisotropy Factor

BU burn-up

C carbon

CEGA Combustion Engineering / General Atomics

$\mathrm{CO}$ carbon monoxide

$\mathrm{CO}_{2} \quad$ carbon dioxide

DOE Department Of Energy

$\mathrm{E}_{\mathrm{n}} \quad$ neutron energy

EFPD equivalent full power day

FIMA fissions per initial metal atom

FCM fully ceramic matrix

FF neutron fast fluence $\left(E_{n}>0.18 \mathrm{MeV}\right)$

FP fission product

HTGR high temperature gas-cooled reactor

INL Idaho National Laboratory

IPyC inner pyrolytic carbon

$\mathrm{Kr} \quad$ krypton

LWR light water reactor

NQA Nuclear Quality Assurance

OPyC outer pyrolytic carbon

PARFUME particle fuel model

$\mathrm{Pd} \quad$ palladium

PyC pyrolytic carbon

$\mathrm{SiC} \quad$ silicon carbide

SMR small modular reactor

TRISO tristructural isotropic

UCO uranium oxy-carbide

UN uranium nitride

$\mathrm{UO}_{2} \quad$ uranium dioxide

U235 uranium 235

Xe xenon 


\section{Modeling and Analysis of FCM UN TRISO Fuel Using the PARFUME Code \\ 1. INTRODUCTION}

Tristructural isotropic (TRISO) fuel particles were originally developed in the 1960s in the United Kingdom as part of the Dragon project. The first nuclear use of TRISO fuel was in experimental High Temperature Gas-cooled Reactor (HTGR) Dragon, followed by use of TRISO fuel in prototype HTGRs THTR-300 in Germany and Fort St. Vrain in the USA. Development of TRISO fuel in the USA was revived through the Department of Energy (DOE) Advanced Gas Reactor (AGR) program with the objective of providing a fuel qualification data set in support of the licensing and operation of an HTGR (Simonds 2012).

Recent advances in TRISO fuel development and performance by the AGR program have triggered interest in other potential applications of TRISO fuel to take advantage of its superior oxidation resistance and fission product (FP) retention capabilities, especially when embedded in a ceramic matrix of silicon carbide as proposed in the design of fully ceramic matrix (FCM) fuel. Such applications include in particular the use of this FCM fuel in LWRs or SMRs (Small Modular Reactors), in which the TRISO fuel could be used at high burn-up. Although original TRISO fuel was developed using uranium dioxide $\left(\mathrm{UO}_{2}\right)$ or uranium oxy-carbide (UCO) kernels, $\mathrm{UN}$ kernels are under investigation by the FCM project to obtain a higher fissile loading compared to $\mathrm{UO}_{2}$ or UCO (Terrani 2012).

This report documents analyses performed to predict the failure probability of TRISO-coated fuel particles during irradiation of FCM fuel under LWR irradiation conditions. The analyses include calculations under nominal irradiation conditions and the assessment of the sensitivity of the subsequent particle failure probability to key irradiation parameters and particle characteristics.

Details associated with the completion of these analyses are provided in the remainder of this document: the scope of the study is detailed in Section 0 along with a brief description of PARFUME, UN TRISO fuel modeling is outlined in Section 0, results are shown in Section 0, conclusions are given in Section 5, and references are listed in Section 6.

Calculations were performed with PARFUME Version 2.22 modified to model uranium nitride fuel and compiled with Intel FORTRAN Compiler 11.1.073 on an SGI Altix ICE 8200 platform operating under SUSE Linux Enterprise Server 10. In addition, this study was conducted in accordance to quality standard NQA-1-2008; 1-a-2009 "Quality Assurance Requirements for Nuclear Facility Applications," published by the American Society of Mechanical Engineers (ASME 2008). 


\section{SCOPE OF THE STUDY}

The objective of this document is to present results of calculations and analyses made by PARFUME on TRISO fuel particles with uranium nitride kernels submitted to irradiation conditions representative of these of Light Water Reactors. These results include:

- Dimensional changes within the TRISO particle, including:

- Kernel swelling

- Buffer densification

- Buffer-IPyC gap formation

- Temperature profile across TRISO particle

- Fission gas pressure and fission gas release

- Radial and tangential stresses

- Fuel failure probability.

The study is limited to the TRISO particle only. In the frame of FCM fuel development, the UN TRISO fuel particles are expected to be embedded in a SiC matrix, but the interactions of the particles with the SiC matrix were not modeled by PARFUME in this study.

\subsection{PARFUME}

The analyses were completed using the particle fuel model computer code PARFUME developed at Idaho National Laboratory (INL). PARFUME is an advanced gas-cooled reactor fuel performance modeling and analysis code (Miller 2009). It has been developed as an integrated mechanistic code that evaluates the thermal, mechanical, and physico-chemical behavior of fuel particles during irradiation to determine the failure probability of a population of fuel particles given the particle-to-particle statistical variations in physical dimensions and material properties that arise from the fuel fabrication process, accounting for all viable mechanisms that can lead to particle failure.

\subsection{TRISO fuel and failure mechanisms}

The coating layers of a TRISO fuel particle, which surround the fuel kernel and buffer, consist of an inner pyrolytic carbon (IPyC) layer, a $\mathrm{SiC}$ layer, and an outer pyrolytic carbon (OPyC) layer. Coated particle fuel exhibits statistical variations in physical dimensions and material properties from particle to particle due to the nature of its fabrication process. Its behavior is also inherently multi-dimensional, further complicating fuel particle analysis. PARFUME physically describes both the mechanical and physico-chemical behaviors of the fuel particle under irradiation, while capturing the statistical nature of the fuel. From these behaviors, the code determines the possible failure of the fuel particle from established failure mechanisms.

Early during irradiation, the shrinkage of the PyC layers puts the $\mathrm{SiC}$ layer in compression. The shrinkage/swelling response of $\mathrm{PyC}$ is highly anisotropic and depends on the irradiation temperature and degree of anisotropy of the PyC (as measured by the Bacon Anisotropy Factor or BAF). Due to this anisotropy in the pyrocarbon shrinkage behavior, the shrinkage histories differ in the radial and tangential directions. The shrinkage in the radial direction reverses to swelling at moderate fast fluence levels, whereas shrinkage in the tangential direction continues to higher fast fluence levels. In addition, as irradiation progresses, the irradiation-induced creep of the PyC layers tends to offset the shrinkage and to relieve some of the compressive stress in the $\mathrm{SiC}$. Concomitantly, fission gas pressure builds up in the kernel and buffer, putting the coating layers in tension as pressure counters the effect of the shrinkage of the IPyC and OPyC layers causing them to push or pull inward on the $\mathrm{SiC}$. The IPyC, SiC, and OPyC act as structural layers to retain this pressure and act as a barrier to the migration of fission products. However, if the gas pressure increases enough, the tangential stress in the SiC layer can eventually 
become tensile, and failure is expected to occur if the stress reaches a value that exceeds the strength of the $\mathrm{SiC}$ for that particle. Whereas the IPyC and OPyC layers both shrink and creep during irradiation, in PARFUME the $\mathrm{SiC}$ response is essentially limited to elastic behavior. Although some swelling of the $\mathrm{SiC}$ layer is anticipated during irradiation, its magnitude is small compared to PyC layers and it is therefore neglected in PARFUME. Consequently, failure of the $\mathrm{SiC}$ results in an instantaneous release of elastic energy that should be sufficient to cause simultaneous failure of the PyC layers.

The most traditional failure mechanism of TRISO fuel is defined as the pressure vessel failure of a one-dimensional spherical particle. The particle is considered one-dimensional because of the symmetry

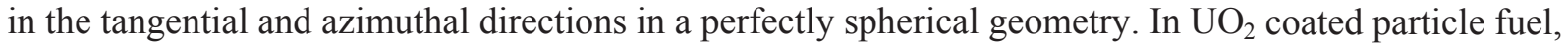
carbon monoxide $(\mathrm{CO})$ production also contributes to the pressure build-up. $\mathrm{CO}$ is produced by reaction of a net excess of oxygen with the carbonaceous buffer. This net excess of free oxygen originates from oxygen released during the fission process that is not consumed by the fission products. However, UN kernels do not contain any oxygen and they are therefore not subject to excessive CO production. As for the free nitrogen produced from fission of the UN fuel, it is consumed by the fission products to form nitride compounds.

In addition to the one-dimensional behavior of a symmetrical spherical fuel particle, several other mechanisms have been identified that can potentially lead to particle failure. PARFUME also considers this multi-dimensional behavior, whose associated potential failure mechanisms consist of (Miller 2009):

- Cracking of the IPyC layer

- Partial debonding of the IPyC from the SiC

- Pressure vessel failure of an aspherical particle

- Kernel/SiC interaction resulting from the Amoeba effect

- Thinning of the SiC layer by palladium attack of the SiC.

IPyC cracking occurs when irradiation-induced shrinkage of the IPyC induces a tensile stress that exceeds the tensile strength in that layer. A radial crack then develops in the IPyC layer that creates local tensile stress in the $\mathrm{SiC}$ layer, leading to possible particle failure. The stress at this point increases as the $\mathrm{PyC}$ layers shrink during irradiation but eventually peaks as creep in the PyC layers overcomes the shrinkage effect.

Partial debonding of the IPyC from the $\mathrm{SiC}$ occurs when irradiation-induced shrinkage of the IPyC induces a radial tensile stress at the interface between the IPyC and $\mathrm{SiC}$ layers that exceeds the bond strength between the two layers.

Asphericity affects the probability of failure at high internal pressure. PARFUME incorporates the effects of asphericity for particles that have a flat facet but are otherwise spherical. Because of discontinuities in the faceted particle geometry, the faceted portion of that particle typically incurs higher stress than spherical or ellipsoidal portions from the pressure of released fission gases. If the pressure build up is high enough, the tensile stress in the faceted portion can exceed the fracture strength of the SiC and lead to particle failure. Effects of ellipsoidal asphericity are small in comparison to faceting and therefore not included in the code (Miller 1994).

Kernel migration, also called Amoeba effect, occurs when the fuel kernel of a particle migrates into the $\mathrm{SiC}$ layer under the influence of a temperature gradient. The kernel is pushed towards the hot side of the TRISO particle by carbon dioxide $\left(\mathrm{CO}_{2}\right)$ and solid-phase carbon $(\mathrm{C})$ produced on the cold side of the particle by $\mathrm{CO}$ migrating down the temperature gradient and reacting as $\mathrm{CO}+\mathrm{CO} \rightarrow \mathrm{CO}_{2}+\mathrm{C}$. Particle failure is assumed to occur when the kernel comes into contact with the $\mathrm{SiC}$ layer. This effect is prominent with $\mathrm{UO}_{2}$ kernels and very small with $\mathrm{UCO}$ kernels. It is expected to be non-existent in UN kernels. 
Fission product palladium $(\mathrm{Pd})$ can attack and penetrate the $\mathrm{SiC}$ layer, causing a thinning of the $\mathrm{SiC}$ thickness that can eventually lead to particle failure. Although particle failure is generally assumed when penetration through the thickness of the $\mathrm{SiC}$ is complete (Miller 2006), PARFUME does not currently treat Pd attack as a standard failure mechanism but rather just computes Pd penetration as a flag for users. The penetration rate is calculated by an Arrhenius function fitted to in-reactor data (Petti 2004). Its applicability to UN TRISO fuel has not been established, so it is not considered in this study.

In all of these thermo-mechanical calculations, the buffer is assumed to have completely detached from the IPyC layer, hence forming a gap. The width of this gap evolves during irradiation as the buffer densifies with increasing neutron fast fluence while the kernel swells with increasing burn-up. This variation of the gap width is important for calculating kernel temperature and fission product diffusion. In the case of failure probability evaluations with PARFUME, the TRISO coating system is mechanically separated from the kernel and buffer. PARFUME was developed to treat the mechanical behavior of a TRISO fuel as a 3-layer problem involving only the PyC and SiC layers. Under its current development state, PARFUME is not designed to deal with any mechanical interaction between the kernel/buffer system and the 3-layer system composed of the outer coating layers. Thus, the validity of PARFUME calculations is limited to cases where the buffer-IPyC gap is still open. Should the buffer-IPyC gap close during irradiation, PARFUME is unable to predict the subsequent fate of the TRISO particle. However, it has been shown that the resulting mechanical interaction between the kernel/buffer system and the three outer coating layers would rapidly lead to the fracture of the SiC (Martin 2002). The approach used in this study was to monitor the width of the buffer-IPyC gap calculated by PARFUME and to force the code to stop when the gap closed during irradiation. When the gap closes, there is no definite answer concerning the fate of the TRISO particle, though its SiC layer would most likely fail, but because PARFUME leaves its domain of validity, at this point reliable calculations can no longer be performed.

To model the multi-dimensional behavior associated with IPyC cracking, debonding, and asphericity PARFUME uses results of the detailed finite element analysis program Abaqus (Abaqus 2007) for cracked, debonded, and/or aspherical particles obtained in conjunction with results from its own closed form one-dimensional solution to make a statistical approximation of the stress levels in any particle (Miller 2002). Because current US TRISO particle fabrication is originally based on German processes, the IPyC-SiC bond strength is set at a value that is considered to be representative for German particles $(100 \mathrm{MPa})$. At this bond strength, IPyC-SiC debonding is not predicted by PARFUME, as can be seen from radial IPyC/SiC stress results in Section 0. As a consequence, debonding was not included in the calculation of the multi-dimensional input parametesrs and it was not considered a potential failure mechanism in this study. For IPyC cracking and particle asphericity, the combined results from PARFUME and Abaqus determine the multi-dimensional statistical parameters required as input parameters. 


\section{UN TRISO FUEL MODELING \\ 3.1 Boundary and Initial Conditions}

PARFUME is designed to evaluate fuel performance under irradiation based on user inputs for irradiation length, neutron fast fluence, and burn-up with a corresponding set of thermal conditions. The prospective irradiation conditions of UN TRISO fuel in an LWR are presented in Table 1.

Table 1. Nominal and boundary irradiation conditions.

\begin{tabular}{|l|c|c|c|}
\hline & Nominal & Lower Bound & Upper Bound \\
\hline EFPD (Days) & 1350 & - & - \\
\hline Fast fluence $\left(\times 10^{25} \mathrm{n} / \mathrm{m}^{2}, \mathrm{E}_{\mathrm{n}}>0.18 \mathrm{MeV}\right)$ & 18 & 15 & 20 \\
\hline Burn-up (\%FIMA) & 19 & 15 & 20 \\
\hline $\begin{array}{l}\text { Irradiation temperature (K) } \\
\text { (applied to the outer OPyC) }\end{array}$ & 850 & 700 & 1100 \\
\hline
\end{tabular}

Fast fluence and burn-up are assumed to increase linearly with irradiation time. The nominal fast fluence reaches $18 \times 10^{25} \mathrm{n} / \mathrm{m}^{2}$ at an irradiation time of $1350 \mathrm{EFPD}$, while the nominal burn-up reaches $19 \%$ FIMA. The nominal value and boundary conditions for the irradiation temperature represent the expected temperature range that UN TRISO fuel will experience in an LWR. Since PARFUME did not take the matrix into consideration in this study, these temperatures are applied to the outer edge of the OPyC layer. This is a fair assumption considering the $\mathrm{SiC}$ thermal conductivity is relatively high, which should lead to a negligible temperature drop in the matrix. From the OPyC boundary temperature, PARFUME calculates the temperature profile between the OPyC and the kernel centerline, taking into account that the temperature profile is affected by the developing buffer-IPyC gap throughout irradiation.

\subsection{Input Parameters}

PARFUME input parameters required to model UN TRISO fuel are listed in Table 2. They include design specifications for the fuel characteristics, particle geometry, and material properties.

The necessity of a high fissile loading leads to maximizing the fissile content while minimizing the amount of structural content. This implies the design of a TRISO particle with a large kernel - typically larger than $500 \mu \mathrm{m}$, a high enrichment, and limited thicknesses for the structural pyrolytic carbon and silicon carbide layers.

The material mechanical properties used in PARFUME to represent shrinkage, swelling, creep, thermal, and elastic behavior of the kernel and coating layers were obtained from a report compiled by the CEGA Corporation (CEGA 1993). Material properties directly incorporated into the PARFUME code source are discussed in the "PARFUME Theory and Models Basis Report" (Miller 2009).

Modifications were made to the PARFUME source code to model UN kernels. These modifications consist of:

- Adding a "Nitrogen to Uranium ratio" variable to allow treatment of uranium nitride fuel

- Including the temperature-dependent conductivity of uranium nitride

- Adapting the fission gas release model for UN kernels

- Adjusting the kernel swelling rate to values representative of UN

- Implementing adequate multi-dimensional input parameters for IPyC cracking and particle asphericity.

The UN thermal conductivity is obtained from nitride fuel properties (Ross 1988), and it is displayed in Appendix A. The fission gas release model for $\mathrm{UN}$ is detailed in Appendix A. The swelling of uranium 
nitride is not well known: swelling rates ranging from 0.6 to more than 1.5\%/\%FIMA were reported over a broad range of temperatures for nitrogen-rich UN fuel (IAEA 2003). This study assumed swelling rate values from 0.5 to $2.0 \% / \%$ FIMA to conservatively cover the possible kernel swelling rate of manufactured UN TRISO fuel. The asphericity mentioned in Table 2 is considered at the $\mathrm{SiC}$ layer level, as required by PARFUME inputs. A value of 1.040 is assumed as a conservative upper limit.

Table 2. Parameters used in the PARFUME modeling of the UN TRISO fuel.

\begin{tabular}{|c|c|c|}
\hline Category & Parameter & $\begin{array}{c}\text { Nominal Value } \\
\pm \text { Standard Deviation } \\
{[\text { Range }]}\end{array}$ \\
\hline Fuel characteristics & $\begin{array}{l}\text { U235 enrichment (wt } \% \text { ) } \\
\text { Carbon/uranium (atomic ratio) } \\
\text { Nitrogen/uranium (atomic ratio) } \\
\text { Uranium contamination fraction } \\
\text { Kernel swelling rate (\%/\%FIMA) }\end{array}$ & $\begin{array}{c}18[15-19.9]^{(\mathrm{a})} \\
0.01[0.01-0.05]^{(\mathrm{a})} \\
0.99[0.95-0.99]^{(\mathrm{a})} \\
0 \\
{[0.5-2.0]}\end{array}$ \\
\hline Particle geometry & $\begin{array}{l}\text { Kernel diameter }(\mu \mathrm{m}) \\
\text { Buffer thickness }(\mu \mathrm{m}) \\
\text { IPyC / OPyC thickness }(\mu \mathrm{m}) \\
\text { SiC thickness }(\mu \mathrm{m}) \\
\text { Particle asphericity@SiC (aspect ratio) }\end{array}$ & $\begin{array}{l}800 \pm 20 \\
75 \pm 8.5 \\
25 \pm 2 \\
35 \pm 1.5 \\
1.040\end{array}$ \\
\hline Material properties & $\begin{array}{l}\text { IPyC/OPyC Weibull modulus } \\
\text { SiC Weibull modulus } \\
\text { IPyC/SiC bond strength (MPa) } \\
\text { PyC Poisson's ratio in creep } \\
\text { PyC creep coefficient amplifier } \\
\text { Kernel density }\left(\mathrm{g} / \mathrm{cm}^{3}\right)^{(\mathrm{b})} \\
\text { Kernel theoretical density }\left(\mathrm{g} / \mathrm{cm}^{3}\right) \\
\text { Buffer density }\left(\mathrm{g} / \mathrm{cm}^{3}\right)^{(b)} \\
\text { Buffer theoretical density }\left(\mathrm{g} / \mathrm{cm}^{3}\right) \\
\text { IPyC/OPyC density }\left(\mathrm{g} / \mathrm{cm}^{3}\right) \\
\text { SiC density }\left(\mathrm{g} / \mathrm{cm}^{3}\right)^{(\mathrm{c})} \\
\text { IPyC/OPyC }(\text { post compact anneal) BAF }\end{array}$ & $\begin{array}{c}9.5 \\
6.0 \\
100.0 \\
0.5 \\
2.0 \\
13.76 \\
14.33 \\
1.00 \\
2.25 \\
1.90 \pm 0.05 \\
3.2 \pm 0.01 \\
1.02 \pm 0.01\end{array}$ \\
\hline Boundary conditions & Ambient pressure $(\mathrm{MPa})$ & 0.1 \\
\hline
\end{tabular}

a. Nominal value and expected range of variation.

b. Standard deviation not used in PARFUME.

c. Nominal value and standard deviation not used in PARFUME. 
The main material properties impacting TRISO particle behavior are:

- Thermal conductivity (kernel and all layers)

- Thermal expansion (kernel and all layers)

- Kernel swelling

- Modulus of elasticity (PyC and SiC)

- Irradiation-induced dimensional changes (buffer and PyC)

- Irradiation-induced creep (buffer and PyC)

- Weibull mean strengths and moduli (PyC and $\mathrm{SiC})$.

In general, application of these material properties in PARFUME is limited to the range of $4 \times 10^{25} \mathrm{n} / \mathrm{m}^{2}$ for neutron fast fluence $\left(\mathrm{E}_{\mathrm{n}}>0.18 \mathrm{MeV}\right)$ and 600 to $1300^{\circ} \mathrm{C}$ for irradiation temperature. The fast fluence dependence of these material properties is less known at higher fast fluence, but it is accounted for in PARFUME by extension of their values at the $4 \times 10^{25} \mathrm{n} / \mathrm{m}^{2}$ fast fluence cut-off. However, fast fluence in this FCM study greatly exceeds this cut-off. PARFUME was therefore modified to include material properties that were identified to be possibly better suited to uranium nitride fuel and its behavior at high fast fluence. The above-mentioned material properties and their more adapted correlations are detailed in Appendix A. In particular, they include a second set (Set 2) of strain rates for the irradiation-induced dimensional changes of the PyC layer, in addition to the strain rates (Set 1) used by default in PARFUME. Set 1 assumes that the PyC tangential shrinkage trend continues at high fast fluence, while Set 2 assumes that the trend will reverse and that PyC swells at high fast fluence in the tangential direction. Both sets of PyC strain rates are plotted against fast fluence in Appendix A.

Also, the nominal temperature of $850 \mathrm{~K}\left(577^{\circ} \mathrm{C}\right)$ is technically below the temperature range of validity of the material properties used in this modeling $\left(600-1300^{\circ} \mathrm{C}\right)$. The application of these material properties therefore rely on extrapolations below their established range of validity.

\subsection{Study Cases}

Table 1 of Section 3.1 and Table 2 of Section 3.2 show the fuel and irradiation characteristics representative of the use of UN TRISO fuel in an LWR environment. These characteristics are defined by nominal design values. Sensitivity around these nominal values has to be evaluated to cover all conditions possibly encountered by UN TRISO fuel in its expected reactor applications. Furthermore, the particle geometry could be modified depending on fuel behavior under irradiation. Table 3 displays the range of expected values for the kernel diameter, layer thicknesses, and PyC density. A set of cases was established to assess the sensitivity of fuel particle failure to the main fuel and irradiation characteristics. The parametric values include:

- $\quad$ Buffer thickness

- $\quad \mathrm{IPyC} / \mathrm{OPyC}$ thickness

- $\quad \mathrm{IPyC} / \mathrm{OPyC}$ density

- Kernel stoichiometry

- Fast fluence

- Burn-up

- U235 enrichment

- OPyC boundary temperature

- Kernel swelling rate

- PyC strain rates. 
PyC strain and kernel swelling are two of the major parameters influencing the mechanical state of the particle. At the beginning of irradiation the combined shrinkage of the buffer and IPyC opens a gap between the two layers. This gap mechanically decouples the kernel and buffer from the three outer coating layers, which are therefore only subjected to the internal pressure of fission gases building up in the kernel and buffer internal voidages and in the buffer-IPyC gap. Then, as irradiation progresses the swelling of the kernel pushes the buffer outwards, while the buffer and IPyC undergo further shrinkage or start experiencing swelling depending on the value of fast fluence and their highly uncertain mechanical properties at this level of fast fluence. Because the $\mathrm{SiC}$ is assumed to undergo no dimensional changes and to stay bonded to the IPyC, the outer radius of the IPyC does not change throughout irradiation. On the other hand, the kernel and buffer are also assumed to stay bonded throughout irradiation. This means that the gap thickness is controlled by the swelling of the kernel on one side, and by the buffer and IPyC shrinkage/swelling on the other side. Therefore, if the kernel swelling rate exceeds the buffer and IPyC shrinkage rates, or even worse if the buffer and/or IPyC start swelling, the buffer-IPyC gap can possibly close during irradiation. As mentioned in Section 2.2, the closing of the gap triggers PARFUME to stop its calculations, and it most likely leads to the fracture of the $\mathrm{SiC}$ layer. The nature of the UN TRISO fuel (large kernel) and its expected irradiation conditions (high burn-up leading to large kernel swelling, and high fast fluence potentially leading to IPyC swelling) can lead to the closing of the buffer-IPyC gap. Combined with the uncertainties about the kernel swelling and $\mathrm{PyC}$ strain rates at high fast fluence, this behavior prompted treatment of the kernel swelling and PyC strain as separate parameters, and determination of acceptable conditions of fast fluence and burn-up under which the gap would remain open. The approach used in the study was to monitor the width of the buffer-IPyC gap, and to stop the calculation should the gap close.

The subsequent study cases are labeled Sx_Ky_Cz, where:

- Sx refers to the data set used for the PyC strain rates $(\mathrm{x}=1$ or 2$)$

- $\quad$ Ky refers to the kernel swelling rate $(y=0.5 / 0.8 / 1.0 / 1.2 / 1.5 / 2.0 \% / \%$ FIMA)

- $\mathrm{Cz}$ refers to the variation of all other parameters.

The $\mathrm{Cz}$ components are displayed in Table 4. $\mathrm{C} 1$ (Nom-1) is the nominal case, serving as a reference for all comparisons.

Other parameters comprise the fuel and irradiation specifications, but they were set to their nominal values and were not varied in this study. These parameters are:

- Kernel initial diameter (nominal value: $800 \mu \mathrm{m}$ )

- Kernel initial density (nominal value: $13.76 \mathrm{~g} / \mathrm{cm}^{3}$ )

- Buffer initial density (nominal value: $1.00 \mathrm{~g} / \mathrm{cm}^{3}$ )

- $\mathrm{SiC}$ thickness (nominal value: $35 \mu \mathrm{m}$ )

- Kernel conductivity (see Appendix A)

- Irradiation length (nominal value: 1350 EFPD).

Table 3. TRISO parameter value ranges used in the UN TRISO study.

\begin{tabular}{|l|c|c|}
\hline Parameter $^{(\mathrm{a})}$ & $\begin{array}{c}\text { Thickness }(\mu \mathrm{m}) \\
\pm \text { Standard Deviation }^{(\mathrm{b})}\end{array}$ & $\begin{array}{c}\text { Density } \\
\left(\mathrm{g} / \mathrm{cm}^{3}\right)\end{array}$ \\
\hline Kernel & $800 \pm 20$ (diameter $)^{3}$ & 13.76 \\
Buffer & $25 \pm 5,50 \pm 7,75 \pm 8.5,100 \pm 10$ & 1.00 \\
IPyC/OPyC & $15 \pm 1.5,25 \pm 2,35 \pm 3$ & $1.85 \pm 0.05,1.90 \pm 0.05$ \\
$\mathrm{SiC}$ & 35 & 3.2 \\
\hline
\end{tabular}

a. Bold values are nominal values.

b. Standard deviations are assessed from AGR manufacturing results. 
Table 4. Study cases.

\begin{tabular}{|c|c|c|c|c|c|c|c|c|}
\hline \multirow[t]{2}{*}{$\operatorname{Case}^{(\mathrm{a})}$} & \multicolumn{2}{|c|}{$\begin{array}{c}\text { Thickness } \\
(\mu \mathrm{m})\end{array}$} & \multirow{2}{*}{$\begin{array}{c}\text { PyC } \\
\text { Density } \\
\left(\mathrm{g} / \mathrm{cm}^{3}\right)\end{array}$} & \multirow{2}{*}{$\begin{array}{c}\text { Kernel } \\
\text { Stoichiometry }\end{array}$} & \multirow{2}{*}{$\begin{array}{c}\text { Fast } \\
\text { fluence } \\
\left(\times 10^{25} \mathrm{n} / \mathrm{m}^{2}\right)\end{array}$} & \multirow{2}{*}{$\begin{array}{l}\text { Burn-up } \\
\text { (\%FIMA) }\end{array}$} & \multirow{2}{*}{$\begin{array}{l}\mathrm{U} 235 \\
\mathrm{wt} \%\end{array}$} & \multirow{2}{*}{$\begin{array}{c}\text { OPyC } \\
\text { Temperature } \\
\text { (K) }\end{array}$} \\
\hline & Buffer & $\mathrm{PyC}$ & & & & & & \\
\hline Nom-1 & 75 & 25 & 1.90 & $\mathrm{U}_{1} \mathrm{~N}_{0.99} \mathrm{C}_{0.01}$ & 18 & 19 & 18 & 850 \\
\hline Sto-2 & 75 & 25 & 1.90 & $\mathrm{U}_{1} \mathrm{~N}_{0.95} \mathrm{C}_{0.05}$ & 18 & 19 & 18 & 850 \\
\hline Buf-3 & 25 & 25 & 1.90 & $\mathrm{U}_{1} \mathrm{~N}_{0.99} \mathrm{C}_{0.01}$ & 18 & 19 & 18 & 850 \\
\hline Buf-4 & 50 & 25 & 1.90 & $\mathrm{U}_{1} \mathrm{~N}_{0.99} \mathrm{C}_{0.01}$ & 18 & 19 & 18 & 850 \\
\hline Buf-5 & 100 & 25 & 1.90 & $\mathrm{U}_{1} \mathrm{~N}_{0.99} \mathrm{C}_{0.01}$ & 18 & 19 & 18 & 850 \\
\hline PyC-6 & 75 & 15 & 1.90 & $\mathrm{U}_{1} \mathrm{~N}_{0.99} \mathrm{C}_{0.01}$ & 18 & 19 & 18 & 850 \\
\hline PyC-7 & 75 & 35 & 1.90 & $\mathrm{U}_{1} \mathrm{~N}_{0.99} \mathrm{C}_{0.01}$ & 18 & 19 & 18 & 850 \\
\hline Den- 8 & 75 & 25 & 1.85 & $\mathrm{U}_{1} \mathrm{~N}_{0.99} \mathrm{C}_{0.01}$ & 18 & 19 & 18 & 850 \\
\hline Par-9 & 75 & 25 & 1.90 & $\mathrm{U}_{1} \mathrm{~N}_{0.99} \mathrm{C}_{0.01}$ & 15 & 15 & 15 & 700 \\
\hline Par-10 & 75 & 25 & 1.90 & $\mathrm{U}_{1} \mathrm{~N}_{0.99} \mathrm{C}_{0.01}$ & 15 & 15 & 15 & 850 \\
\hline Par-11 & 75 & 25 & 1.90 & $\mathrm{U}_{1} \mathrm{~N}_{0.99} \mathrm{C}_{0.01}$ & 15 & 15 & 15 & 1100 \\
\hline Par-12 & 75 & 25 & 1.90 & $\mathrm{U}_{1} \mathrm{~N}_{0.99} \mathrm{C}_{0.01}$ & 15 & 19 & 18 & 700 \\
\hline Par-13 & 75 & 25 & 1.90 & $\mathrm{U}_{1} \mathrm{~N}_{0.99} \mathrm{C}_{0.01}$ & 15 & 19 & 18 & 850 \\
\hline Par-14 & 75 & 25 & 1.90 & $\mathrm{U}_{1} \mathrm{~N}_{0.99} \mathrm{C}_{0.01}$ & 15 & 19 & 18 & 1100 \\
\hline Par-15 & 75 & 25 & 1.90 & $\mathrm{U}_{1} \mathrm{~N}_{0.99} \mathrm{C}_{0.01}$ & 15 & 20 & 19.9 & 700 \\
\hline Par-16 & 75 & 25 & 1.90 & $\mathrm{U}_{1} \mathrm{~N}_{0.99} \mathrm{C}_{0.01}$ & 15 & 20 & 19.9 & 850 \\
\hline Par-17 & 75 & 25 & 1.90 & $\mathrm{U}_{1} \mathrm{~N}_{0.99} \mathrm{C}_{0.01}$ & 15 & 20 & 19.9 & 1100 \\
\hline Par-18 & 75 & 25 & 1.90 & $\mathrm{U}_{1} \mathrm{~N}_{0.99} \mathrm{C}_{0.01}$ & 18 & 15 & 15 & 700 \\
\hline Par-19 & 75 & 25 & 1.90 & $\mathrm{U}_{1} \mathrm{~N}_{0.99} \mathrm{C}_{0.01}$ & 18 & 15 & 15 & 850 \\
\hline Par-20 & 75 & 25 & 1.90 & $\mathrm{U}_{1} \mathrm{~N}_{0.99} \mathrm{C}_{0.01}$ & 18 & 15 & 15 & 1100 \\
\hline Par-21 & 75 & 25 & 1.90 & $\mathrm{U}_{1} \mathrm{~N}_{0.99} \mathrm{C}_{0.01}$ & 18 & 19 & 18 & 700 \\
\hline Par-22 & 75 & 25 & 1.90 & $\mathrm{U}_{1} \mathrm{~N}_{0.99} \mathrm{C}_{0.01}$ & 18 & 19 & 18 & 1100 \\
\hline Par-23 & 75 & 25 & 1.90 & $\mathrm{U}_{1} \mathrm{~N}_{0.99} \mathrm{C}_{0.01}$ & 18 & 20 & 19.9 & 700 \\
\hline Par-24 & 75 & 25 & 1.90 & $\mathrm{U}_{1} \mathrm{~N}_{0.99} \mathrm{C}_{0.01}$ & 18 & 20 & 19.9 & 850 \\
\hline Par-25 & 75 & 25 & 1.90 & $\mathrm{U}_{1} \mathrm{~N}_{0.99} \mathrm{C}_{0.01}$ & 18 & 20 & 19.9 & 1100 \\
\hline Par-26 & 75 & 25 & 1.90 & $\mathrm{U}_{1} \mathrm{~N}_{0.99} \mathrm{C}_{0.01}$ & 20 & 15 & 15 & 700 \\
\hline Par-27 & 75 & 25 & 1.90 & $\mathrm{U}_{1} \mathrm{~N}_{0.99} \mathrm{C}_{0.01}$ & 20 & 15 & 15 & 850 \\
\hline Par-28 & 75 & 25 & 1.90 & $\mathrm{U}_{1} \mathrm{~N}_{0.99} \mathrm{C}_{0.01}$ & 20 & 15 & 15 & 1100 \\
\hline Par-29 & 75 & 25 & 1.90 & $\mathrm{U}_{1} \mathrm{~N}_{0.99} \mathrm{C}_{0.01}$ & 20 & 19 & 18 & 700 \\
\hline Par-30 & 75 & 25 & 1.90 & $\mathrm{U}_{1} \mathrm{~N}_{0.99} \mathrm{C}_{0.01}$ & 20 & 19 & 18 & 850 \\
\hline Par-31 & 75 & 25 & 1.90 & $\mathrm{U}_{1} \mathrm{~N}_{0.99} \mathrm{C}_{0.01}$ & 20 & 19 & 18 & 1100 \\
\hline Par-32 & 75 & 25 & 1.90 & $\mathrm{U}_{1} \mathrm{~N}_{0.99} \mathrm{C}_{0.01}$ & 20 & 20 & 19.9 & 700 \\
\hline Par-33 & 75 & 25 & 1.90 & $\mathrm{U}_{1} \mathrm{~N}_{0.99} \mathrm{C}_{0.01}$ & 20 & 20 & 19.9 & 850 \\
\hline Par-34 & 75 & 25 & 1.90 & $\mathrm{U}_{1} \mathrm{~N}_{0.99} \mathrm{C}_{0.01}$ & 20 & 20 & 19.9 & 1100 \\
\hline
\end{tabular}

a. Bold values are nominal values. 
Appendix B lists the calculation status of all study cases for both sets of strain rates and for kernel swelling rate values. A red status means that the gap has closed during irradiation, and the calculation was stopped. Cases with red status should be considered as a regime in which the use of UN TRISO fuel is highly questionable under LWR irradiation conditions. A blue status means that the $75-\mu \mathrm{m}$ buffer is too thin and should be thickened to $100 \mu \mathrm{m}$ to provide more physical volume in the particle to accommodate dimensional changes and hence allow for PARFUME calculations to continue. A green status means that the buffer-IPyC gap remains open throughout irradiation and that PARFUME was able to calculate the mechanical behavior of the TRISO particle (a "blue" calculation is therefore "green" if the buffer thickness is set to $100 \mu \mathrm{m})$.

As can be seen, all calculations using "Set 2" of the PyC strain rates failed. The calculations using "Set 1" only succeeded if the kernel swelling rate was kept below 1.0\%/\%FIMA, and only for a kernel swelling rate of $0.5 \% / \%$ FIMA would a $75-\mu \mathrm{m}$ buffer be suitable. In all other cases, the calculations were stopped because the buffer-IPyC gap closed during irradiation. This means that, in these cases, the fast fluence and burn-up target values are too high for the TRISO particle to survive all the way to the end of irradiation. The achievable target values are therefore lower than the projected LWR values. As an illustration, Figure 1 shows the maximum fast fluence (FF) and burn-up (BU) values that could be achieved depending on the prospective irradiation target values at $850 \mathrm{~K}$ for a kernel swelling rate of $1 \% / \%$ FIMA and using "Set 2" of the PyC strain rates. Plots for the other kernel swelling rates and PyC strain rates are given in Appendix C. Each line represent one set of these FF/BU values, including the nominal values (18/19) and the combinations using the upper and lower bound values $(15 / 15,15 / 20$, $20 / 15,20 / 20$ ). Note that the curves for the upper and lower bound values 20/20 and 15/15 are superimposed. The green part shows the range of FF/BU that would be achievable, and the red part show the range where the buffer-IPyC gap closes. The curves were obtained for a particle with an $880-\mu \mathrm{m}$ diameter kernel coated with a $60-\mu \mathrm{m}$ thick buffer. These values represent a deviation of $+4 \sigma /-4 \sigma$ from the expected acceptable diameter and buffer sizes of $800 / 100 \mu \mathrm{m}$ (see Table 3 and Appendix B). Fabrication of the AGR TRISO fuel showed that oversized kernels tend to be coated with undersized buffers, even though the trend is not very pronounced. It can anyways be expected that fabrication of UN TRISO fuel may lead to a small fraction of such particles, which will be the first to fail under harsh irradiation conditions. Considering a fraction of about $10^{-4}$ of a particle batch lies outside the $\pm 4 \sigma$ range, this limit was considered acceptable to determine the limits of the irradiation domain. A nominal buffer thickness of $75 \mu \mathrm{m}$ would lower even further the limits obtained in Figure 1 and Appendix C. 


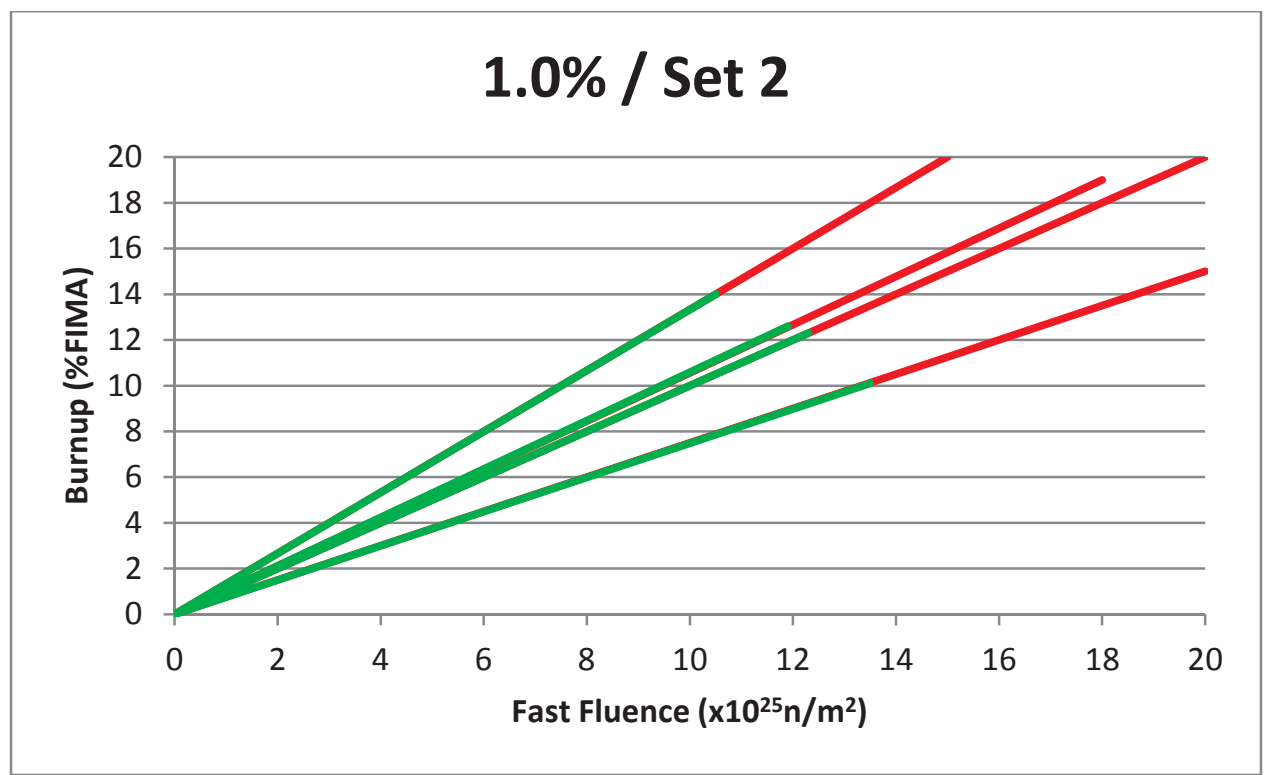

Figure 1. Maximum achievable fast fluence and burn-up at $850 \mathrm{~K}$ for a kernel swelling rate of $1 \% / \%$ FIMA and "Set 2" of PyC strain rates. 


\section{RESULTS}

PARFUME was run with its Fast Integration scheme to calculate the probability of particle failure of UN TRISO fuel under LWR irradiation conditions. An example of a PARFUME input deck is given in Appendix D. Results calculated by PARFUME include:

- Dimensional changes within the TRISO particle, including:

- Kernel swelling

- $\quad$ Buffer densification

- Buffer-IPyC gap formation

- Temperature profile across TRISO particle

- Fission gas pressure and fission gas release

- Radial and tangential stresses

- Fuel failure probability.

In PARFUME, the probability of fuel particle failure is assessed from the following failure mechanisms:

- Pressure vessel failure

- Cracking of the IPyC layer

- Partial debonding of the IPyC from the SiC

- Amoeba effect.

Pressure vessel failure can occur in both spherical and aspherical particles. Aspherical particles are more prone to failing under pressure as their faceted portions are more sensitive to pressure. The calculations conservatively assume that all particles in the compacts have an asphericity of 1.040 (see Section 2.2). As explained in Section 2.2, partial debonding of the IPyC from the $\mathrm{SiC}$ is not expected to be able to lead to particle failure because of the assumed high IPyC-SiC bond strength. It is therefore not considered a potential failure mechanism in this study. Also, because of the nature of the kernel, Amoeba effect is not a potential failure mechanism for UN fuel.

Because of the calculation limitations due to the closing buffer-IPyC discussed in Section 3.3, only in a handful of cases were failure probabilities calculated. The list includes (see Section 3.3 for the nomenclature):

- Nominal fast fluence and burn-up target values at various kernel swelling rates and temperatures:

- S1_K05_C1, S1_K05_C21, and S1_K05_C22

- S1_K08_C1,S1_K08_C21, and S1_K08_C22

- S1_K10_C1, S1_K10_C21, and S1_K10_C22.

- Low fast fluence and high burn-up target values at various temperatures:

- S1_K05_C15, S1_K05_C16, and S1_K05_C17.

- High fast fluence and low burn-up target values at nominal temperature:

- S1_K05_C27.

- Nominal irradiation conditions at various PyC thicknesses:

- S1_K05_C6, and S1_K05_C7.

These cases were chosen to illustrate results at both typical and extreme conditions. The irradiation temperature was shown to have a limited impact on the mechanical state of the TRISO particle, so it was not systematically used. 


\subsection{Dimensional changes}

Figure 2, Figure 3 and Figure 4 illustrate the dimensional changes occurring during irradiation for the nominal case S1_K05_C1.

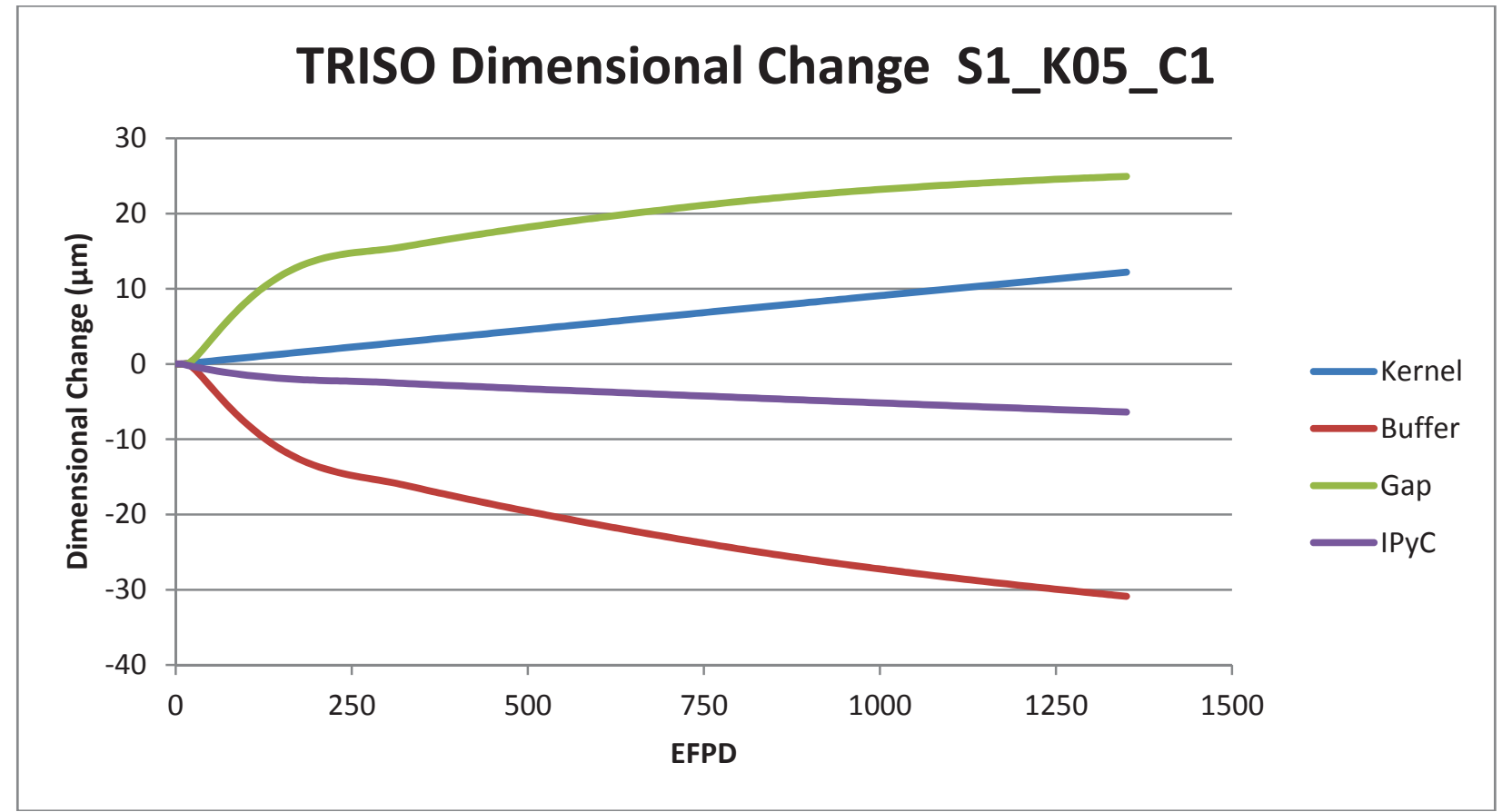

Figure 2. Dimensional changes of the kernel, buffer, buffer-IPyC gap, and IPyC layer throughout irradiation for nominal case S1_K05_C1.

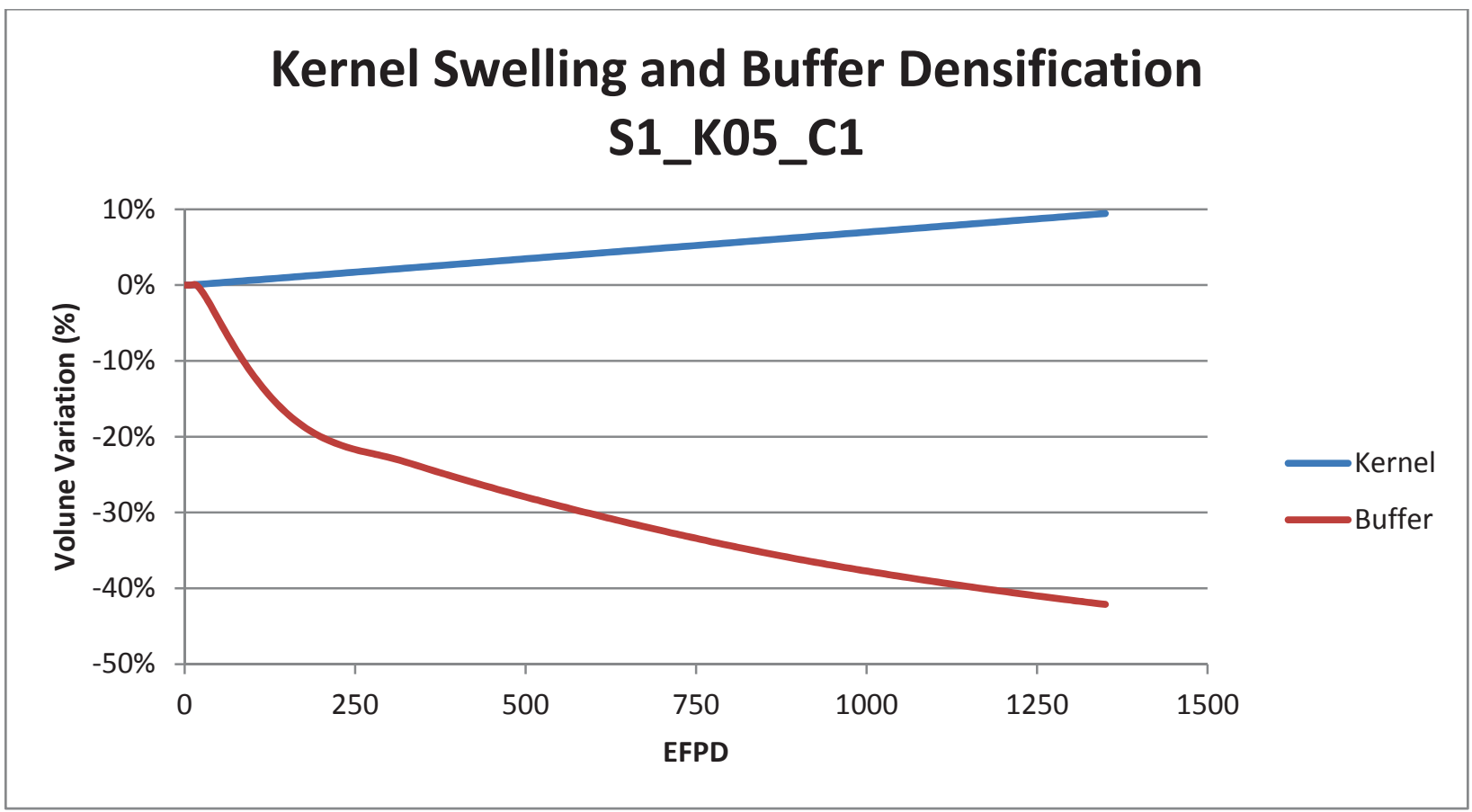

Figure 3. Kernel swelling and buffer densification throughout irradiation for nominal case S1_K05_C1. 


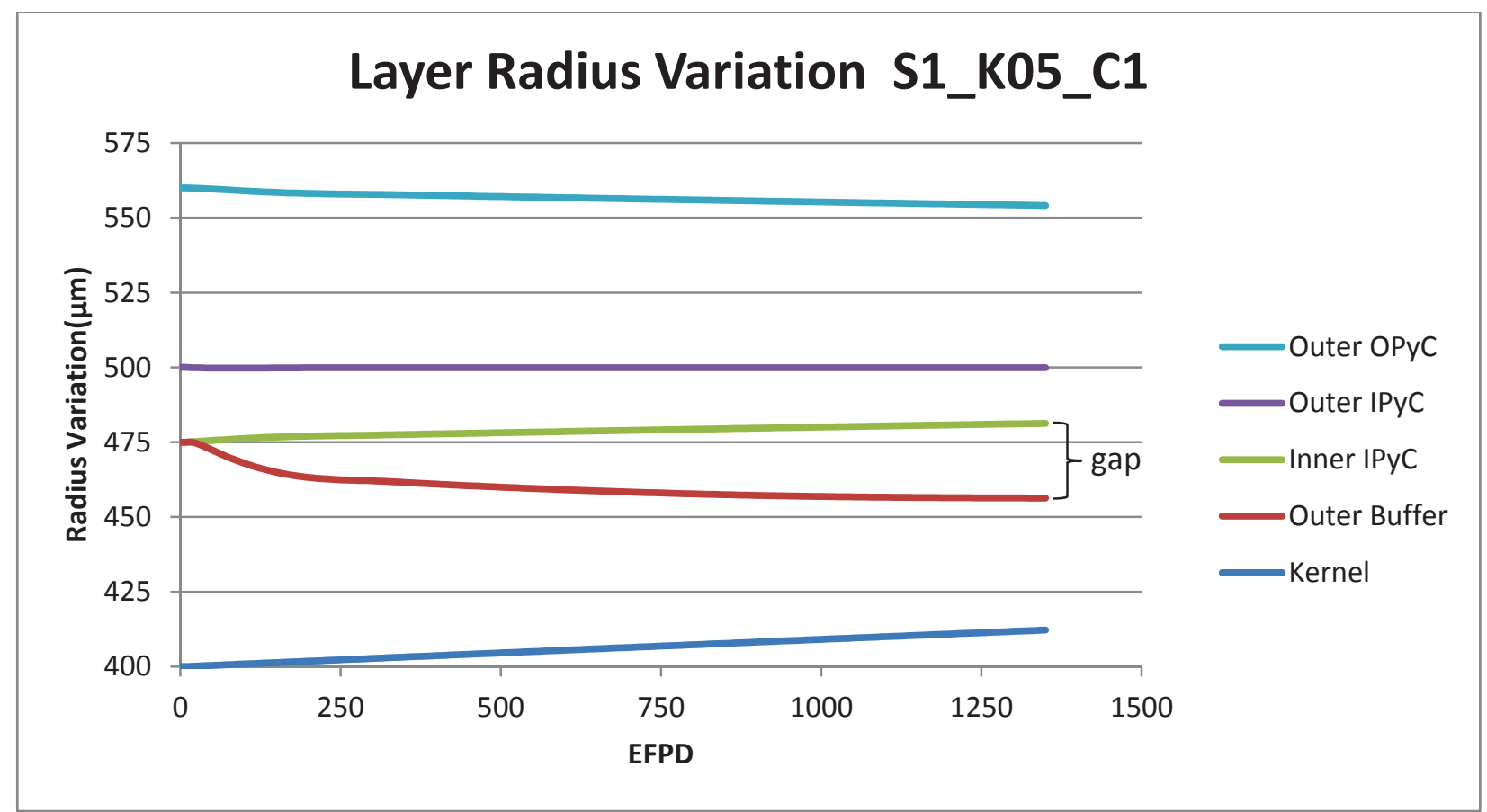

Figure 4. Layer radius variation throughout irradiation for nominal case S1_K05_C1.

The kernel swelling is easily obtained from its volumetric change rate of $0.5 \% / \%$ FIMA, which for the nominal burn-up target of 19\%FIMA leads to an increase of roughly $10 \%$ in volume (cf. Figure 2 ) and $12 \mu \mathrm{m}$ in radius (cf. Figure 4). For the PyC strain rates used in this case, the buffer shrinks inwards on its outer side, while being pushed outwards by the swelling kernel. The net effect is a decrease of its thickness by about $31 \mu \mathrm{m}$ or $42 \%$ of its initial volume. The inner PyC side shrinks outwards by about 6 $\mu \mathrm{m}$ while, by assumption, its outer side is bonded to the $\mathrm{SiC}$ layer which is not subjected to any dimensional changes. The combined shrinkages of the buffer and IPyC open a gap of final width equal to about $25 \mu \mathrm{m}(31-12+6=25)$. Table 5 summarizes these dimensional changes for all the computed cases.

As can be seen, the kernel radius change is only determined by the burn-up target value, while the densification of the buffer and IPyC depends on the temperature-dependent and fluence-dependent shrinkage. The buffer-IPyC gap results from the intrinsic shrinkage of both the buffer and the IPyC layer, and the swelling of the kernel. For a given fast fluence, Table 5 shows that an increasing irradiation temperature amplifies the buffer shrinkage and decreases the IPyC shrinkage by a larger amount, resulting in a narrowing gap. The decrease in shrinkage of the $\mathrm{PyC}$ is a consequence of its tangential strain being lower at high temperatures when the fast fluence is beyond the cut-off value of $4 \times 10^{25} \mathrm{n} / \mathrm{m}^{2}$. An opposite trend is observed at low fluence (see Appendix A). On the other hand, at a given temperature, a higher fast fluence increases both the buffer and IPyC shrinkages resulting in a widening gap (note that in Table 5, the buffer dimensional change is a net value combining the buffer densification due to kernel swelling and the buffer inherent shrinkage).

Under nominal conditions, as the thickness of the IPyC layer is modified (S1_K05_C6 and S1_K05_C7), the gap is impacted by the IPyC shrinkage: a thicker PyC layer shrinks more in proportion, and its shrinkage therefore opens a wider gap.

When the kernel swelling rate increases (see cases S1_K08 and S1_K10 in Table 5, which are based on a $100-\mu \mathrm{m}$ nominal buffer rather than the $75-\mu \mathrm{m}$ nominal thickness of cases S1_K05), the buffer shrinks slightly more. The shrinkage of the IPyC, on the other hand, is not affected by the swelling of the kernel. As a result, the buffer is pushed further outwards by the more swollen kernel, which reduces the 
buffer-IPyC gap. For even larger kernel swelling rates, the gap eventually closes during irradiation (see Appendix B).

Table 5. Dimensional changes $(\mu \mathrm{m})$ at the end of irradiation.

\begin{tabular}{|c|c|c|c|c|c|c|c|}
\hline Case & $\begin{array}{l}\text { Fast fluence } \\
\left(\times 10^{25} \mathrm{n} / \mathrm{m}^{2}\right)\end{array}$ & $\begin{array}{l}\text { Burn-up } \\
\text { (\%FIMA) }\end{array}$ & $\begin{array}{c}\text { Temperature } \\
(K)\end{array}$ & Kernel $^{(\mathrm{a})}$ & Buffer $^{(a)}$ & $\mathrm{IPyC}^{(\mathrm{a})}$ & Buffer-IPyC Gap ${ }^{(a)}$ \\
\hline $\mathrm{S} 1 \_\mathrm{K} 05 \_\mathrm{C} 1$ & 18 & 19 & 850 & 12.2 & -30.9 & -6.4 & 25.0 \\
\hline $\mathrm{S} 1$ K05_C2 $1^{(\mathrm{b})}$ & 18 & 19 & 700 & 12.2 & -30.2 & -7.6 & 25.5 \\
\hline $\mathrm{S} 1 \mathrm{~K} 05$ C22 & 18 & 19 & 1100 & 12.2 & -32.1 & -4.1 & 24.0 \\
\hline $\mathrm{S} 1 \mathrm{~K} 05 \mathrm{C} 15^{(\mathrm{b})}$ & 15 & 19.9 & 700 & 12.8 & -28.4 & -6.6 & 22.2 \\
\hline S1_K05_C16 & 15 & 19.9 & 850 & 12.8 & -29.1 & -5.6 & 21.8 \\
\hline $\mathrm{S} 1 \quad \mathrm{~K} 05 \quad \mathrm{C} 17$ & 15 & 19.9 & 1100 & 12.8 & -30.4 & -3.8 & 21.3 \\
\hline $\mathrm{S} 1 \_$K05 C27 & 20 & 15 & 850 & 9.7 & -31.3 & -6.9 & 28.4 \\
\hline $\mathrm{S} 1 \_\mathrm{K} 05 \_\mathrm{C} 6$ & 18 & 19 & 850 & 12.2 & -30.8 & -3.8 & 22.4 \\
\hline $\mathrm{S} 1 \_\mathrm{K} 05 \_\mathrm{C} 7$ & 18 & 19 & 850 & 12.2 & -30.9 & -9.0 & 27.6 \\
\hline $\mathrm{S} 1 \_\mathrm{K} 08 \_\mathrm{C} 1$ & 18 & 19 & 850 & 19.2 & -41.3 & -6.4 & 28.4 \\
\hline $\mathrm{S} 1 \_\mathrm{K} 08 \_\mathrm{C} 21^{(\mathrm{b})}$ & 18 & 19 & 700 & 19.2 & -40.4 & -7.6 & 28.7 \\
\hline S1_K08_C22 & 18 & 19 & 1100 & 19.2 & -42.8 & -4.2 & 27.7 \\
\hline $\mathrm{S} 1 \_\mathrm{K} 10 \_\mathrm{C} 1$ & 18 & 19 & 850 & 23.7 & -42.2 & -6.4 & 24.8 \\
\hline $\mathrm{S} 1 \_\mathrm{K} 10 \_\mathrm{C} 21^{(\mathrm{b})}$ & 18 & 19 & 700 & 23.7 & -41.4 & -7.6 & 25.1 \\
\hline $\mathrm{S} 1 \mathrm{~K} 10 \mathrm{C} 22$ & 18 & 19 & 1100 & 23.7 & -43.8 & -4.2 & 24.1 \\
\hline
\end{tabular}

a. A positive value denotes swelling, while a negative value implies shrinkage.

b. IPyC shrinkage at $700 \mathrm{~K}$ is slightly under-predicted because the irradiation-induced creep coefficient is expected to be over-estimated at temperatures below $600^{\circ} \mathrm{C}$ therefore over-relaxing the shrinkage (see Appendix A). Consequently, the gaps at $700 \mathrm{~K}$ are slightly under-estimated.

Figure 5 shows the dimensional changes in the TRISO particle for case S1_K20_C1, in which the kernel swelling rate is increased to $2.0 \% / \%$ FIMA. In this case, the kernel radius increases by about $11 \%$ throughout irradiation, and the buffer-IPyC gap closes after 1160 EFPD when the outer side of the buffer comes into contact with the inner side of the IPyC layer. 


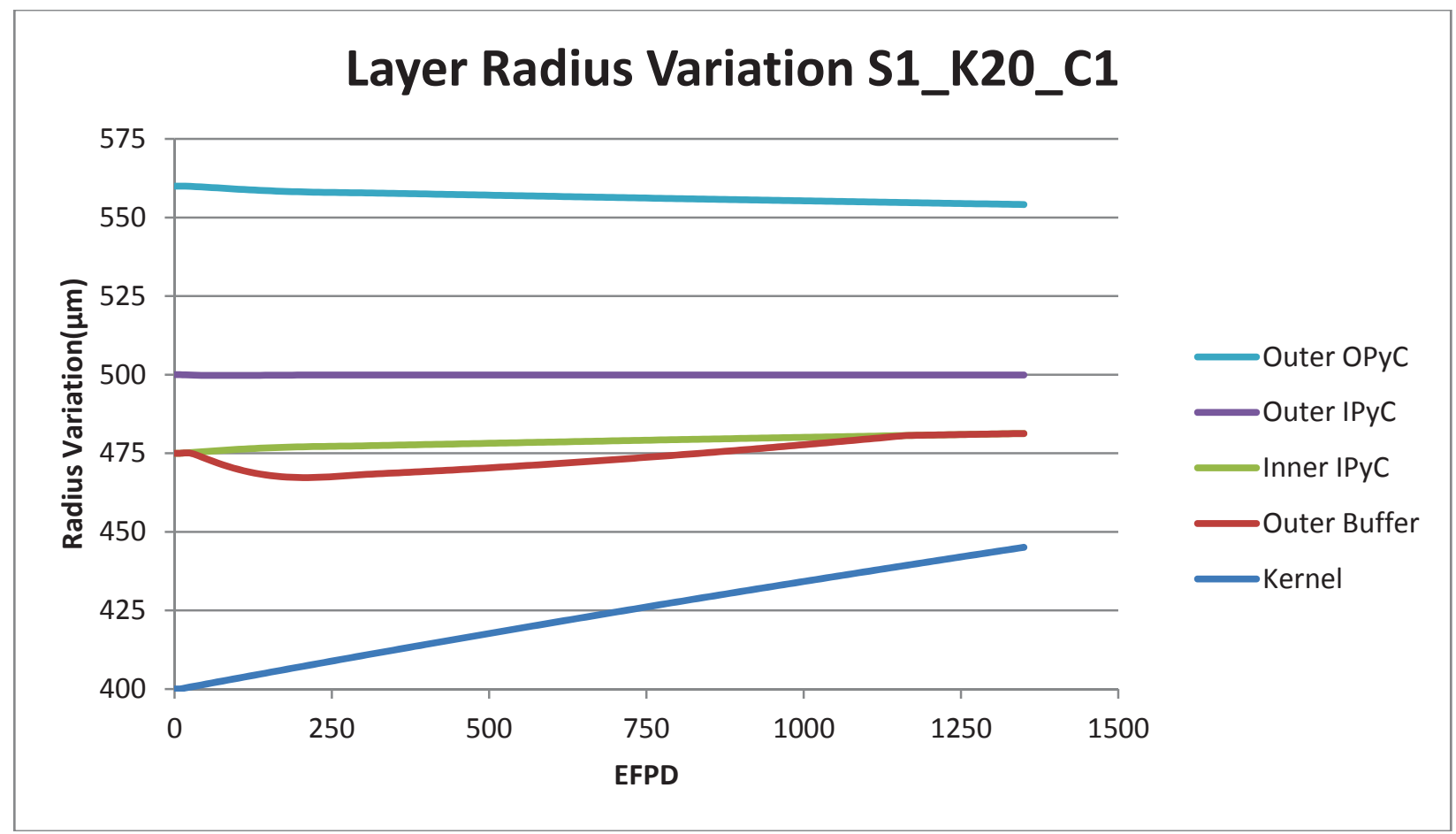

Figure 5. Layer radius variation throughout irradiation for case S1_K20_C1.

\subsection{Temperature Profiles and Gas Pressure}

Figure 6 and Figure 7 illustrate the temperature increase in the kernel and buffer throughout irradiation and the temperature profile in the TRISO particle at the end of irradiation for the nominal case S1_K05_C1. Figure 8 and Figure 9 give the fission gas pressure, production and release as a function of time for the nominal case S1_K05_C1. 


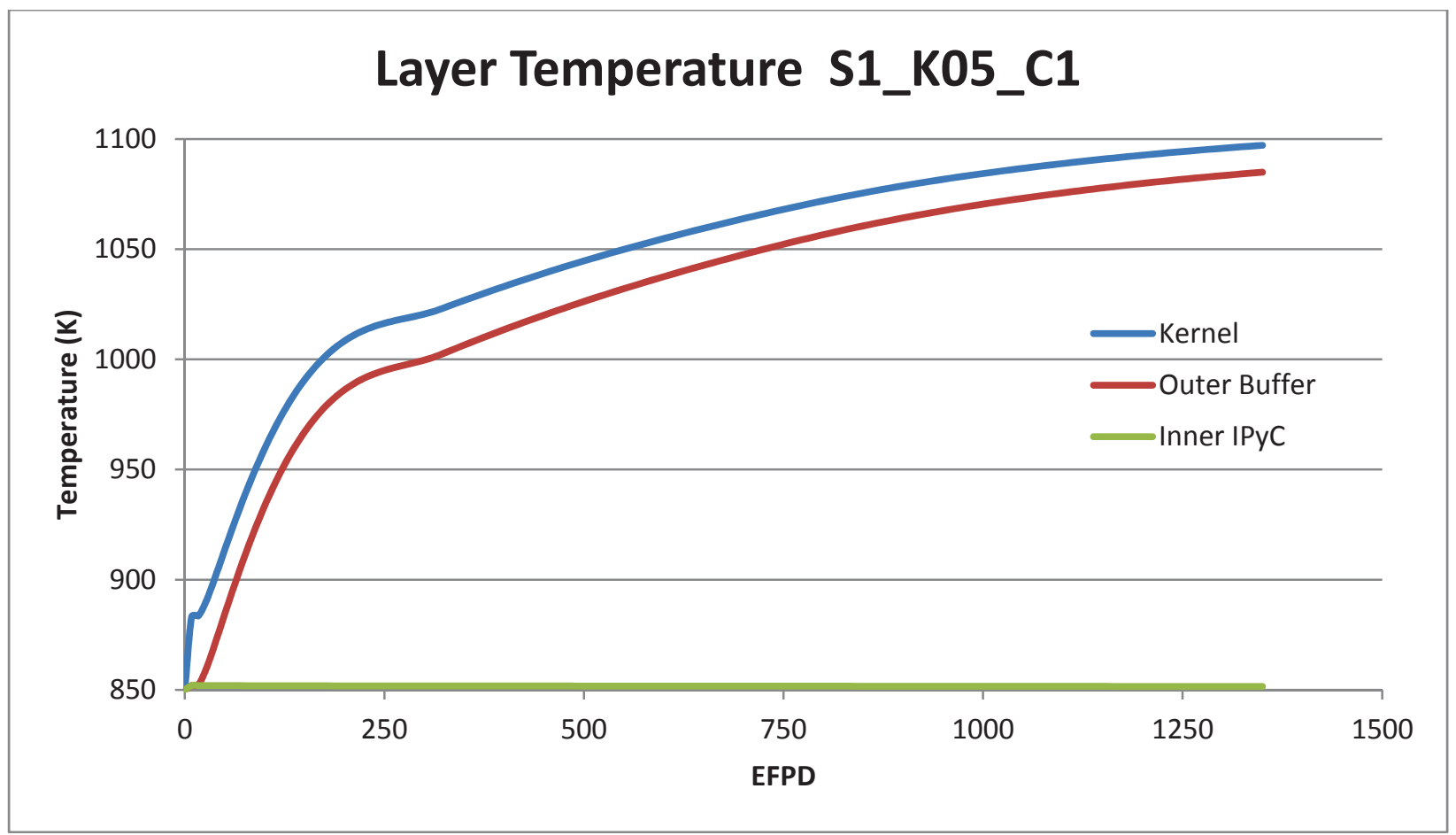

Figure 6. Kernel, buffer and IPyC temperatures throughout irradiation for nominal case S1_K05_C1.

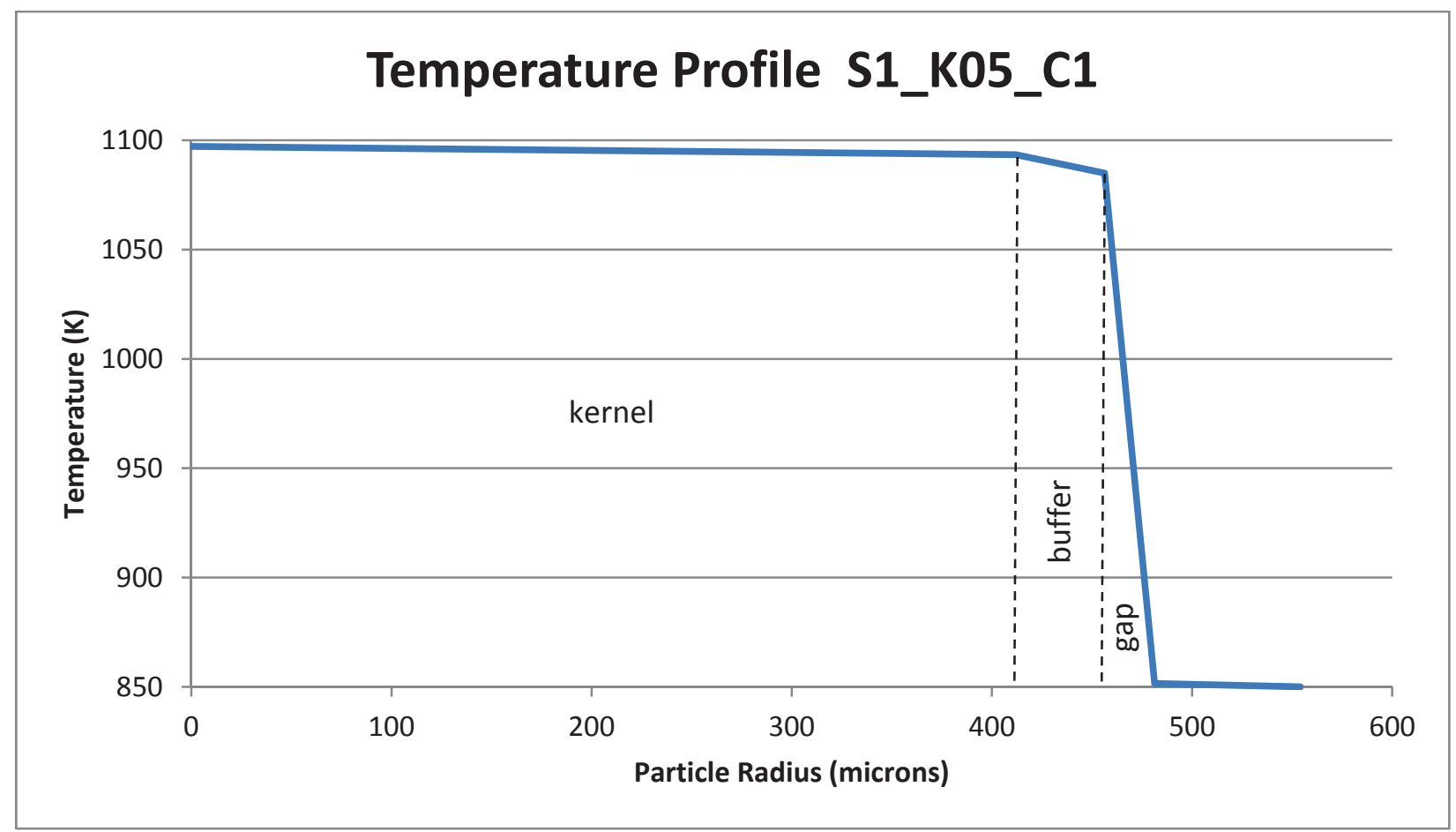

Figure 7. Temperature profile across the TRISO particle at the end of irradiation for nominal case S1_K05_C1. 


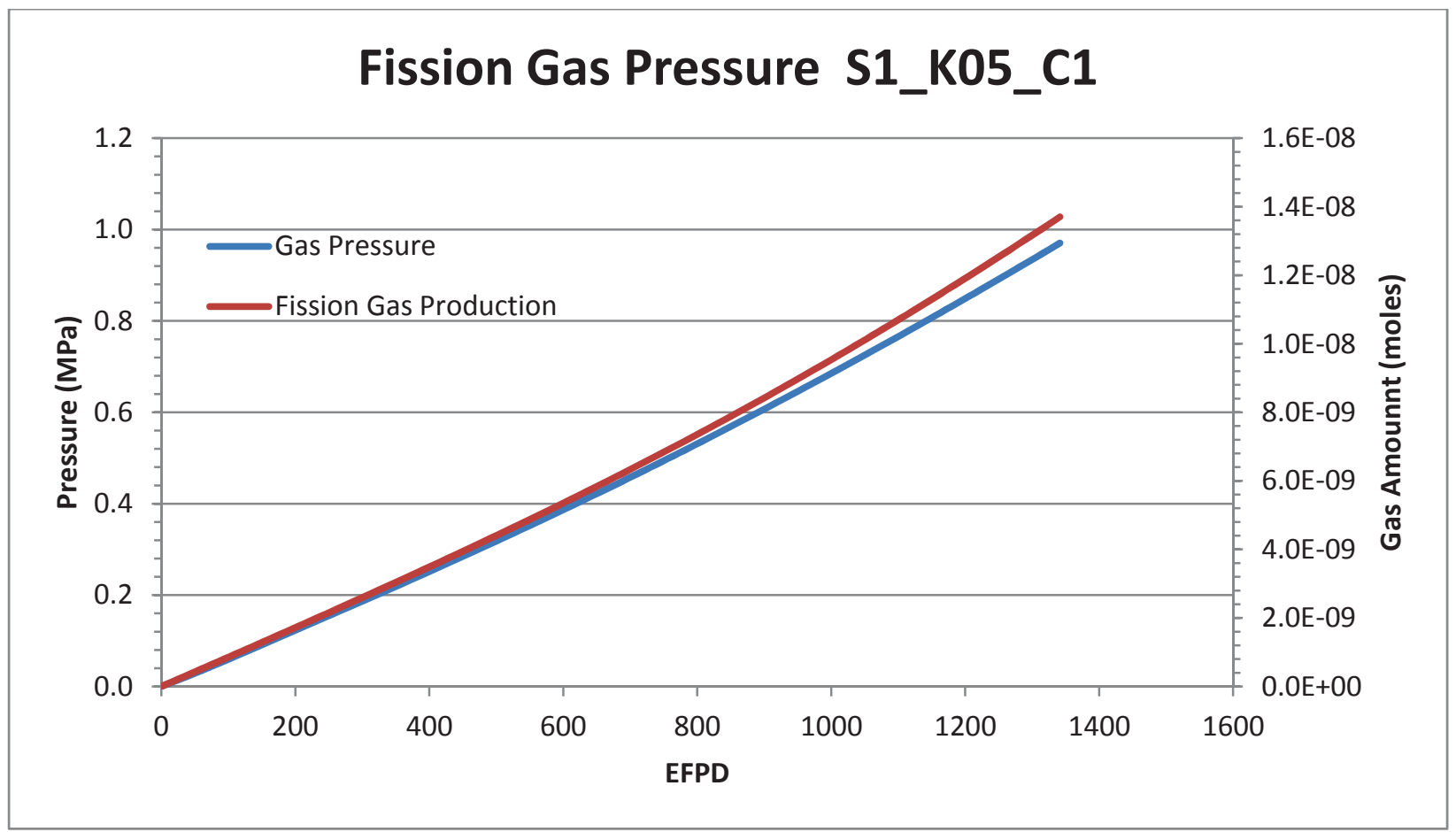

Figure 8. Fission gas pressure inside the TRISO particle throughout irradiation for nominal case S1_K05_C1.

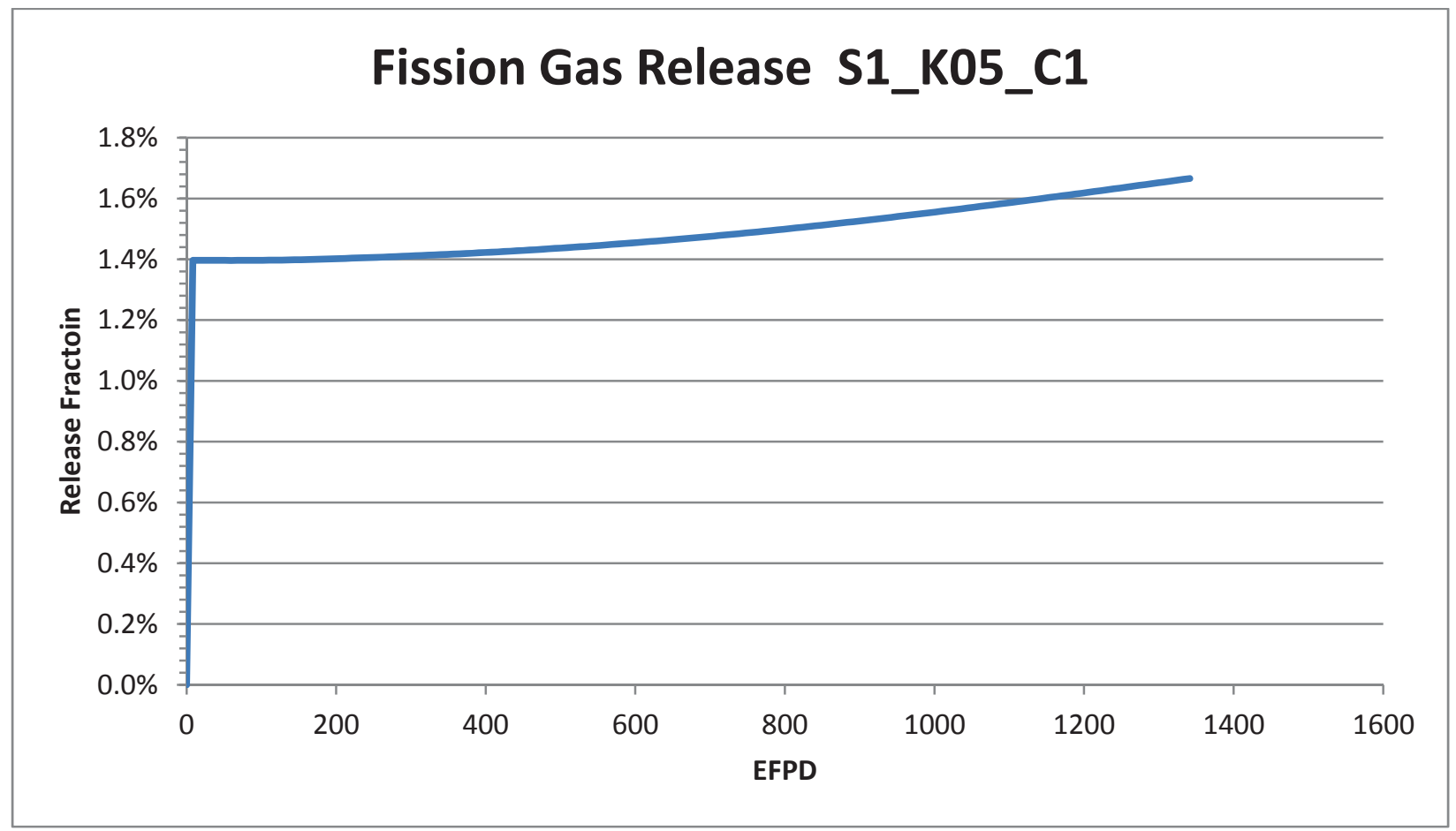

Figure 9. Fission gas release from the UN kernel throughout irradiation for nominal case S1_K05_C1. 
In the nominal case, the outer OPyC temperature is kept at a temperature of $850 \mathrm{~K}$ (see Section 3.1). Considering the relatively high thermal conductivities in the $\mathrm{PyC}$ and $\mathrm{SiC}$ layers, and to a lesser extent in the UN kernel (see Appendix A), the temperature drops are mostly observed in the buffer-IPyC gap and in the buffer. Figure 6 shows the temperature evolution at the inner PyC side (green), at the outer buffer side (red), and at the kernel center (blue). The difference between the green and red curves shows the temperature drop due to the buffer-IPyC gap, while the difference between the red and the blue curves represents the temperature drop due to thermal conductivity in the buffer and kernel.

Figure 7 is a plot of the temperature profile across the TRISO particle at the end of irradiation, showing a slight temperature drop in the densified buffer followed by a significant drop in the buffer-IPyC gap.

Table 6 displays the temperature values at the end of irradiation for the nominal case and all computed cases. In first order approximation, the temperature drops across the TRISO particle in the various computed cases can be related to the size of the gap, where the largest drop is encountered. The fast fluence and burn-up target values are responsible for the width of the gap through shrinkage of the buffer and IPyC, and swelling of the kernel. Typically, a higher fast fluence (respectively lower burn-up) would lead to a larger shrinkage of the buffer (respectively lower swelling of the kernel) thus maximizing the width of the gap and the temperature drop across it. It could therefore be expected that a higher fast fluence or a lower burn-up target values (or the combination of both) would lead to a higher kernel centerline temperature. Cases S1_K05_C1 and S1_K05_C27 show that it is not necessarily the case. The reason is that the burn-up target value also has a direct effect on the fission rate which, together with the increase of kernel volume from swelling, establishes the particle power density that dictates the temperature drops in the kernel, buffer and gap. In other words, choosing a lower burn-up target value leads to a lower fission rate (which is directly proportional to the burn-up) and to a slightly smaller swollen kernel. The subsequent power density (proportional to the ratio of the fission rate to the kernel volume) turns out to be lower for case S1_K05_C27 than it is for case S1_K05_C1. Consequently, even with a larger gap, case S1_K05_C27 ends up with a lower kernel centerline temperature than case S1_K05_C1.

As the kernel swelling rate increases, temperatures are impacted by the size of the buffer-IPyC gap, and to a lesser extent by the size of the kernel and buffer because the conductivity is much lower in the gap and therefore has the bigger effect on temperature drops. Table 5 shows that for cases S1_K08 and S1_K10 the larger gap is achieved for the lower swelling rate, and consequently a lower swelling rate will lead to a larger temperature drop across the TRISO particle and therefore to a higher fuel centerline temperature, as seen in Table 6. Also, for a given burn-up, the larger kernel will generate a smaller power density, leading to a smaller temperature drop across the TRISO particle.

As seen in Section 4.1, the initial thickness of the IPyC layer impacts the size of the developing buffer-IPyC gap: a thicker PyC layer shrinks more in proportion, and it therefore opens a wider gap. As a result, a larger temperature drop across the TRISO particle and a higher fuel centerline temperature are obtained for a thicker initial IPyC layer. The thickness of the PyC layers itself does not impact the temperature profile as the conductivity in the PyC leads to a near-zero temperature drop in the PyC layers.

As can be seen in Figure 8 and Figure 9, the fission gas release is very limited in UN fuel at the nominal temperature of $850 \mathrm{~K}$. For the nominal case, it corresponds to a kernel centerline temperature of about $1100 \mathrm{~K}$ (see Table 6 ), where release is dominated by recoil. This low release triggers a very low pressure inside the TRISO particle. As the irradiation temperature rises to $1100 \mathrm{~K}(\sim 1300 \mathrm{~K}$ centerline), the diffusive release kicks in and slightly increases the overall release and internal pressure (see case S1_K05_C22 in Table 6). The diffusive release is generally low because the effective diffusive coefficient derived from UN release data is small in the LWR temperature range (see Appendix A).

The internal pressure decreases with higher kernel swelling rates (see cases S1_K08 and S1_K10 in Table 6) as a consequence of two effects: on the one hand a relatively bigger kernel has a relatively 
smaller rim likely to release fission gas by recoil, and on the other hand the lower temperature experienced by the more swollen kernel will limit diffusive gas release. As a consequence, a TRISO particle with a kernel swelling at a rate of 1.0\%/\%FIMA will experience a smaller internal pressure than if its kernel swelled at a rate of $0.8 \% / \%$ FIMA. The difference in internal pressure between cases with a kernel swelling rate of $0.5 \% / \%$ FIMA and cases with larger swelling rates must also take into account the smaller void volume resulting from a $75-\mu \mathrm{m}$ buffer (compared to 100- $\mu \mathrm{m}$ ) which leads to a larger internal pressure, all other things being equal.

Table 6. Temperatures and fission gas pressure and release fractions at the end of irradiation.

\begin{tabular}{|l|c|c|c|c|c|c|c|c|}
\hline Case & $\begin{array}{c}\text { Fast } \\
\text { fluence } \\
\left(\times 10^{25} \mathrm{~m}^{2}\right)\end{array}$ & $\begin{array}{c}\text { Burn-up } \\
(\% \text { FIMA })\end{array}$ & $\begin{array}{c}\text { Temp. } \\
(\text { K) }\end{array}$ & $\begin{array}{c}\text { Kernel } \\
\text { Temp. } \\
(\mathrm{K})\end{array}$ & $\begin{array}{c}\text { Inner } \\
\text { Buffer } \\
\text { Temp. } \\
(\mathrm{K})\end{array}$ & $\begin{array}{c}\text { Outer } \\
\text { Buffer } \\
\text { Temp. } \\
(\mathrm{K})\end{array}$ & $\begin{array}{c}\text { Pressure } \\
(\mathrm{MPa})\end{array}$ & $\begin{array}{c}\text { Release } \\
\text { Fraction }\end{array}$ \\
\hline S1_K05_C1 & 18 & 19 & 850 & 1097 & 1093 & 1085 & 0.97 & $1.7 \%$ \\
\hline S1_K05_C21 & 18 & 19 & 700 & 984 & 980 & 971 & 0.71 & $1.4 \%$ \\
\hline S1_K05_C22 & 18 & 19 & 1100 & 1301 & 1298 & 1290 & 3.03 & $4.1 \%$ \\
\hline S1_K05_C15 & 15 & 19.9 & 700 & 965 & 961 & 950 & 0.75 & $1.4 \%$ \\
\hline S1_K05_C16 & 15 & 19.9 & 850 & 1082 & 1077 & 1067 & 0.99 & $1.6 \%$ \\
\hline S1_K05_C17 & 15 & 19.9 & 1100 & 1291 & 1287 & 1278 & 3.08 & $4.0 \%$ \\
\hline S1_K05_C27 & 20 & 15 & 850 & 1073 & 1070 & 1064 & 0.70 & $1.6 \%$ \\
\hline S1_K05_C6 & 18 & 19 & 850 & 1076 & 1072 & 1063 & 0.97 & $1.6 \%$ \\
\hline S1_K05_C7 & 18 & 19 & 850 & 1119 & 1115 & 1107 & 0.97 & $1.7 \%$ \\
\hline S1_K08_C1 & 18 & 19 & 850 & 1106 & 1102 & 1091 & 0.75 & $1.7 \%$ \\
\hline S1_K08_C21 & 18 & 19 & 700 & 991 & 987 & 976 & 0.54 & $1.4 \%$ \\
\hline S1_K08_C22 & 18 & 19 & 1100 & 1312 & 1308 & 1299 & 2.39 & $4.4 \%$ \\
\hline S1_K10_C1 & 18 & 19 & 850 & 1076 & 1073 & 1062 & 0.69 & $1.6 \%$ \\
\hline S1_K10_C21 & 18 & 19 & 700 & 959 & 955 & 944 & 0.51 & $1.4 \%$ \\
\hline S1_K10_C22 & 18 & 19 & 1100 & 1286 & 1283 & 1274 & 2.18 & $4.1 \%$ \\
\hline
\end{tabular}

\subsection{Stress Levels}

Figure 10 and Figure 11 illustrate the radial and tangential stresses in the 3-layer mechanical system throughout irradiation for the nominal case S1_K05_C1, while Table 7 summarizes these stress levels for all the computed cases.

The maximum radial tensile stress at the IPyC/SiC interface ( 20 MPa) is much lower than the bond strength between the two layers (100 MPa), validating the assumption of no debonding between the IPyC and the $\mathrm{SiC}$.

The tangential stress exhibits a typical shape: early during irradiation, the shrinkage of the PyC layers puts the $\mathrm{SiC}$ layer in compression. As irradiation progresses, the irradiation-induced creep of the PyC layers tends to offset their shrinkage and to relieve some of the compressive stress in the SiC. The stress curves consequently peak around $1 \times 10^{25} \mathrm{n} / \mathrm{m}^{2}$. In addition, the fission gas pressure building up in the kernel and buffer puts the coating layers in tension, though this tension is limited because of the low pressure level in the TRISO particle (see Section 4.2). As the fluence nears $4 \times 10^{25} \mathrm{n} / \mathrm{m}^{2}$, the code exits its domain of validity and the $\mathrm{PyC}$ strain rates get extrapolated from their values at the fast fluence cut-off. 
Table 7. Stress levels in the 3-layer mechanical system at the end of irradiation.

\begin{tabular}{|c|c|c|c|c|c|c|c|c|}
\hline \multirow{2}{*}{ Case } & \multirow{2}{*}{$\begin{array}{c}\text { Fast } \\
\text { fluence } \\
\left(\times 10^{25} \mathrm{n} / \mathrm{m}^{2}\right)\end{array}$} & \multirow{2}{*}{$\begin{array}{l}\text { Burn-up } \\
\text { (\%FIMA) }\end{array}$} & \multirow{2}{*}{$\begin{array}{l}\text { Temp. } \\
(K)\end{array}$} & \multicolumn{2}{|c|}{$\begin{array}{c}\text { Radial Stress }^{(\mathrm{a})} \\
(\mathrm{MPa})\end{array}$} & \multicolumn{3}{|c|}{$\begin{array}{c}\text { Tangential Stress }{ }^{(a)} \\
(\mathrm{MPa})\end{array}$} \\
\hline & & & & $\begin{array}{c}\mathrm{IPyC} / \mathrm{SiC} \\
\text { (Max) }\end{array}$ & $\begin{array}{l}\mathrm{SiC} / \mathrm{OPyC} \\
\text { (Min) }\end{array}$ & $\begin{array}{l}\text { IPyC } \\
\text { (Max) }\end{array}$ & $\begin{array}{c}\mathrm{SiC} \\
\text { (Min) }\end{array}$ & $\begin{array}{l}\text { OPyC } \\
\text { (Max) }\end{array}$ \\
\hline $\mathrm{S} 1 \_\mathrm{K} 05 \_\mathrm{C} 1$ & 18 & 19 & 850 & 19 & -16 & 205 & -255 & 165 \\
\hline $\mathrm{S} 1 \_\mathrm{K} 05 \_\mathrm{C} 21^{(\mathrm{b})}$ & 18 & 19 & 700 & 16 & -13 & 172 & -214 & 137 \\
\hline S1_K05_C22 & 18 & 19 & 1100 & 17 & -14 & 181 & -227 & 146 \\
\hline $\mathrm{S} 1 \mathrm{~K} 05 \mathrm{C} 15^{(\mathrm{b})}$ & 15 & 19.9 & 700 & 16 & -13 & 172 & -214 & 137 \\
\hline S1_K05_C16 & 15 & 19.9 & 850 & 17 & -16 & 205 & -255 & 165 \\
\hline S1_K05_C17 & 15 & 19.9 & 1100 & 19 & -14 & 181 & -226 & 146 \\
\hline S1_K05_C27 & 20 & 15 & 850 & 19 & -16 & 205 & -255 & 165 \\
\hline S1_K05_C6 & 18 & 19 & 850 & 11 & -10 & 198 & -154 & 172 \\
\hline S1_K05_C7 & 18 & 19 & 850 & 27 & -21 & 213 & -356 & 163 \\
\hline S1_K08_C1 & 18 & 19 & 850 & 18 & -15 & 204 & -255 & 166 \\
\hline $\mathrm{S} 1 \_\mathrm{K} 08 \_\mathrm{C} 21^{(\mathrm{b})}$ & 18 & 19 & 700 & 15 & -13 & 171 & -214 & 138 \\
\hline S1_K08 C22 & 18 & 19 & 1100 & 16 & -13 & 180 & -227 & 147 \\
\hline S1_K10_C1 & 18 & 19 & 850 & 18 & -15 & 204 & -255 & 166 \\
\hline $\mathrm{S} 1 \_\mathrm{K} 10 \_\mathrm{C} 21^{(\mathrm{b})}$ & 18 & 19 & 700 & 15 & -13 & 171 & -214 & 138 \\
\hline S1_K10_C22 & 18 & 19 & 1100 & 16 & -13 & 180 & -227 & 147 \\
\hline
\end{tabular}

a. A positive value denotes a tensile stress, while a negative value implies a compressive stress.

b. Absolute stress values at $700 \mathrm{~K}$ are slightly under-predicted because the irradiation-induced creep coefficient is expected to be over-estimated at temperatures below $600^{\circ} \mathrm{C}$ therefore over-relaxing the stresses (see Appendix A). 


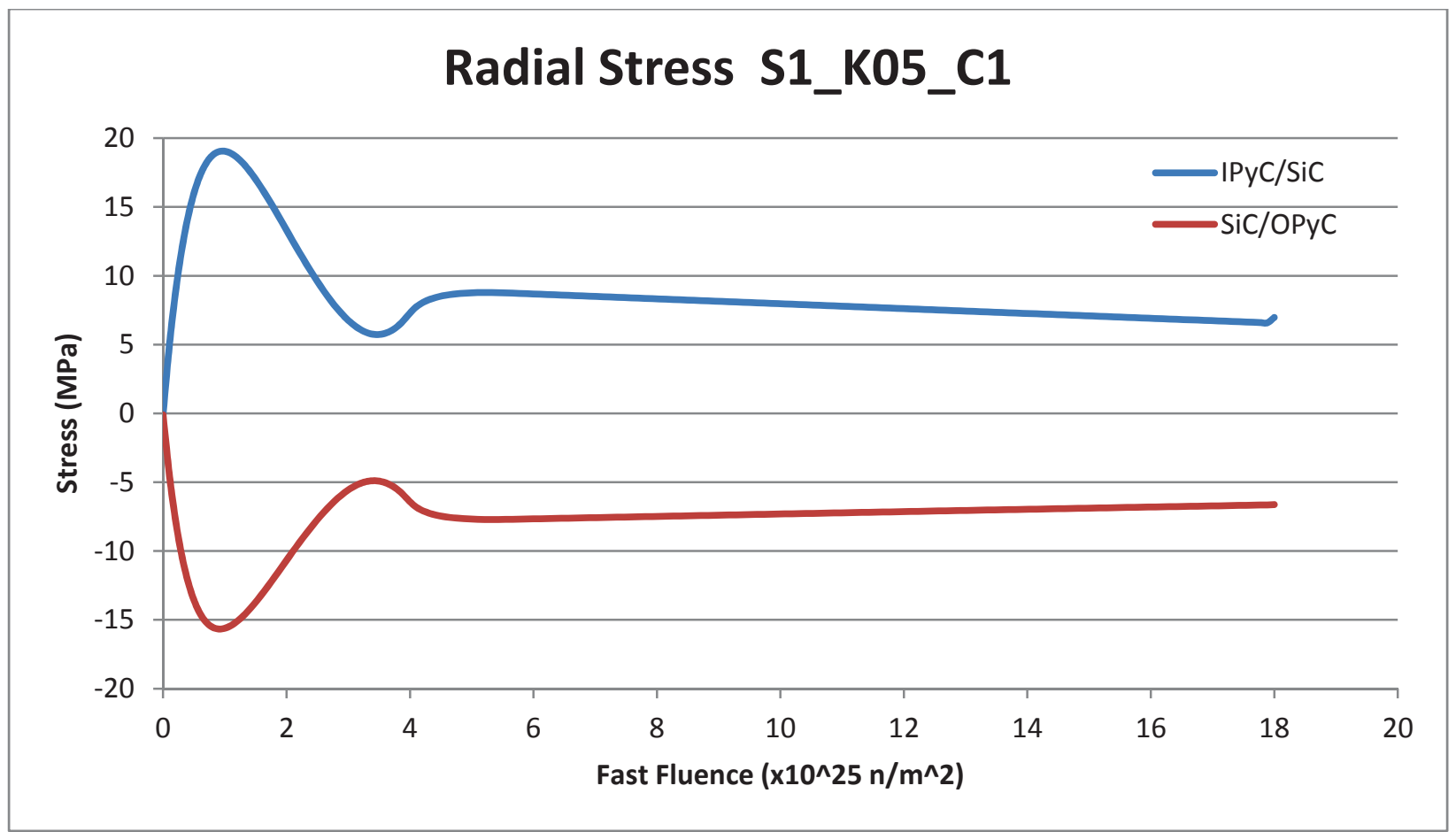

Figure 10. Radial stress at the $\mathrm{IPyC} / \mathrm{SiC}$ and $\mathrm{SiC} / \mathrm{OPyC}$ interfaces throughout irradiation for nominal case S1_K05_C1.

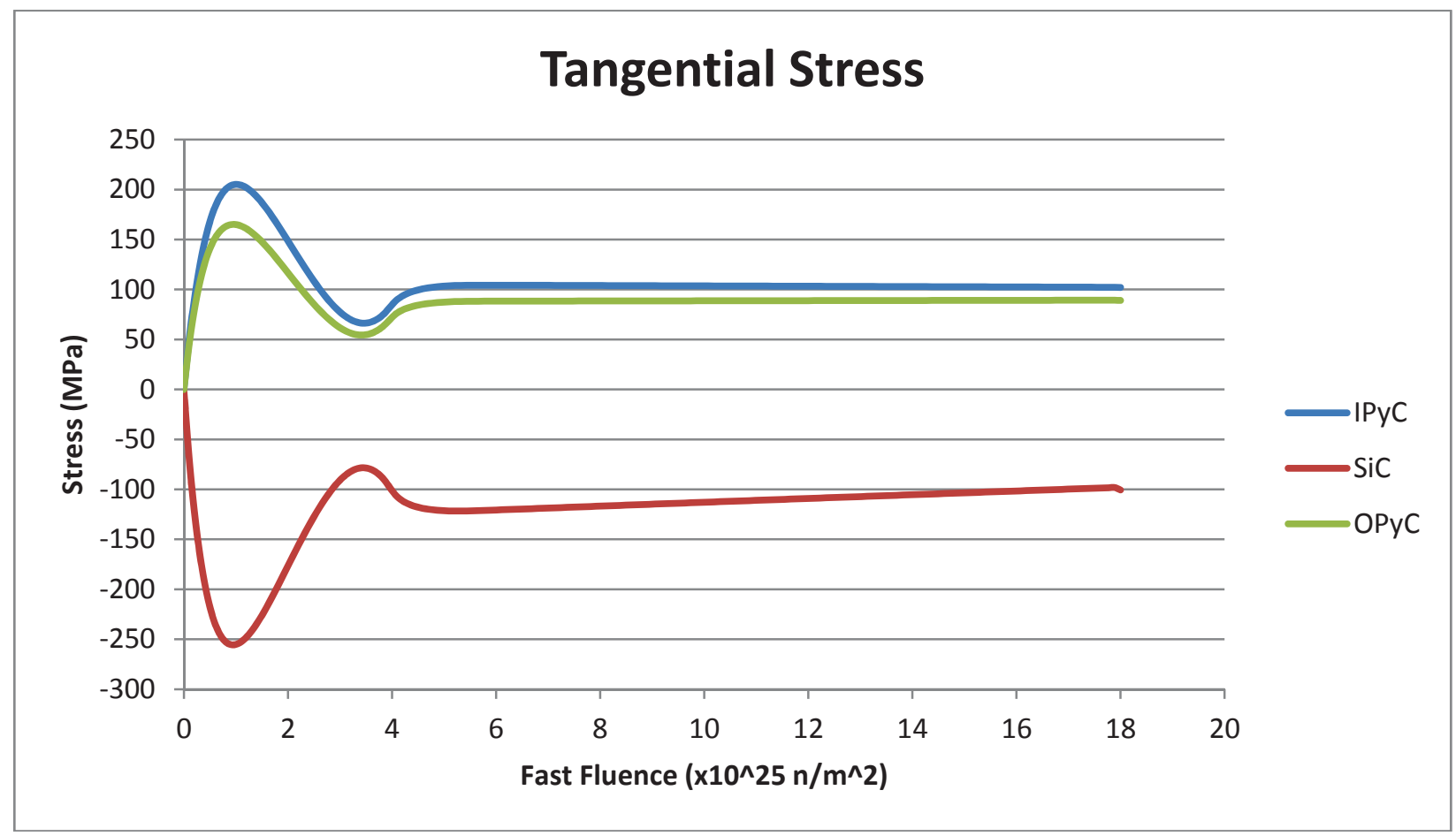

Figure 11. Tangential stress in IPyC, SiC and OPyC layers throughout irradiation for nominal case S1_K05_C1. 
As can be seen in Table 7, there is little temperature effect on the maximum tensile and compressive stresses. This is due to the relatively slow variation of the PyC strain and creep with temperature at temperatures below $1000^{\circ} \mathrm{C}$. The values reported at $700 \mathrm{~K}$ are nonetheless slightly under-predicted because the irradiation-induced creep of the PyC layers is over-estimated at temperatures below $600^{\circ} \mathrm{C}$. The validity range of the irradiation-induced creep coefficient is $600-1200^{\circ} \mathrm{C}$, where the creep shows an increasing trend with temperature. The higher value computed at $700 \mathrm{~K}$, compared to $850 \mathrm{~K}$, is an artifact of the temperature correlation resulting from the fit of the data between 600 and $1200^{\circ} \mathrm{C}$ (see Appendix A). A lower creep coefficient should be expected at $700 \mathrm{~K}$ but, considering the slow variation of the PyC strain and creep at low temperatures, the effect on the maximum stresses is not expected to be large.

Also, because IPyC cracking typically occurs very early during irradiation (around $1 \times 10^{25} \mathrm{n} / \mathrm{m}^{2}$ ), the fast fluence and burn-up target values do not impact the resulting maximum stresses.

The relatively larger shrinkage experienced by a thicker IPyC layer (case S1_K05_C7) puts more stress on the $\mathrm{SiC}$ layer, resulting in a larger tangential compressive stress early during irradiation. It also increases the tangential stress in the IPyC layer, making it more prone to cracking. Furthermore, it also significantly increases the radial stress at the IPyC/SiC interface, therefore increasing the pressure load on the $\mathrm{SiC}$ layer. Table 7 shows that the maximum tangential stress increases by $\sim 40 \%$ when the thickness of IPyC layer is increased from 25 to $35 \mu \mathrm{m}$, and reduced by $~ 65 \%$ when the thickness is decreased to 15 $\mu \mathrm{m}$. The radial stress at the $\mathrm{IPyC} / \mathrm{SiC}$ interface varies by roughly $\pm 40 \%$ when the thickness of the IPyC layer is modified by $\pm 10 \mu \mathrm{m}$. The opposite effects are observed for thinner PyC layers.

Kernel swelling has no effect on the stress level in the structural layers, most notably because the UN TRISO fuel releases very little fission gas at the LWR temperatures, and therefore experiences very low internal pressure.

\subsection{Failure probabilities}

Table 8 displays the SiC failure probabilities for all the cases calculated in this study. They are very low for the nominal particle geometry with probabilities lower than $5 \times 10^{-5}$. Failure is limited to IPyC cracking and pressure vessel failure, as debonding of the $\mathrm{SiC}$ from the IPyC and kernel migration are not potential failure mechanisms in the case of UN TRISO fuel under FCM conditions.

The contribution to $\mathrm{SiC}$ failure due to pressure is very limited because of the low gas release from the UN kernel at the moderate LWR temperatures (see Section 4.2). In addition, the stress exerted by the PyC layers on the $\mathrm{SiC}$ is lower than the $\mathrm{SiC}$ fracture strength, and it therefore does not contribute significantly to pressure vessel failure, even when asphericity comes into play. Consequently, the probability of SiC failure is largely dominated by the cracking of the IPyC.

At a given fast fluence, a temperature increase leads to a slight decrease in maximum tangential and radial stresses on the IPyC and SiC layers, as seen in Table 7. As a consequence, the probability of IPyC cracking and $\mathrm{SiC}$ failure are both decreased with rising temperatures. The gas pressure increases with temperature, but its level is still fairly low and its contribution to $\mathrm{SiC}$ failure remains limited.

As explained in Section 4.3, fast fluence and burn-up target values have no impact on the stress levels in the TRISO particle, and therefore they do not impact the $\mathrm{SiC}$ failure probability. Also, a thicker IPyC layer (case S1_K05_C7) puts more stress on the SiC layer, hence resulting in an increasing contribution to its failure, which is enhanced by particle asphericity. 
Table 8. Failure probabilities at the end of irradiation.

\begin{tabular}{|c|c|c|c|c|c|c|c|}
\hline \multirow[b]{2}{*}{ Case } & \multirow{2}{*}{$\begin{array}{c}\text { Fast } \\
\text { fluence } \\
\left(\times 10^{25} \mathrm{n} / \mathrm{m}^{2}\right)\end{array}$} & \multirow[b]{2}{*}{$\begin{array}{l}\text { Burn-up } \\
\text { (\%FIMA) }\end{array}$} & \multirow[b]{2}{*}{$\begin{array}{c}\text { Temperature } \\
\text { (K) }\end{array}$} & \multicolumn{3}{|c|}{ Probability of SiC failure } & \multirow[b]{2}{*}{$\begin{array}{c}\text { Probability } \\
\text { of IPyC } \\
\text { cracking }\end{array}$} \\
\hline & & & & $\begin{array}{c}\text { Contribution } \\
\text { due to IPyC } \\
\text { cracking }\end{array}$ & $\begin{array}{c}\text { Contribution } \\
\text { due to } \\
\text { pressure }\end{array}$ & Total & \\
\hline $\mathrm{S} 1 \_\mathrm{K} 05 \_\mathrm{C} 1$ & 18 & 19 & 850 & $4.95 \times 10^{-5}$ & $1.70 \times 10^{-15}$ & $4.95 \times 10^{-5}$ & $4.49 \times 10^{-1}$ \\
\hline $\mathrm{S} 1 \_\mathrm{K} 05 \_\mathrm{C} 21^{(\mathrm{a})}$ & 18 & 19 & 700 & $1.27 \times 10^{-5}$ & $8.26 \times 10^{-16}$ & $1.27 \times 10^{-5}$ & $1.15 \times 10^{-1}$ \\
\hline S1_K05_C22 & 18 & 19 & 1100 & $9.32 \times 10^{-6}$ & $3.36 \times 10^{-12}$ & $9.32 \times 10^{-6}$ & $2.01 \times 10^{-1}$ \\
\hline $\mathrm{S} 1 \_\mathrm{K} 05 \_\mathrm{C} 15^{(\mathrm{a})}$ & 15 & 19.9 & 700 & $1.29 \times 10^{-5}$ & $1.03 \times 10^{-15}$ & $1.29 \times 10^{-5}$ & $1.16 \times 10^{-1}$ \\
\hline $\mathrm{S} 1 \_\mathrm{K} 05 \_\mathrm{C} 16$ & 15 & 19.9 & 850 & $4.94 \times 10^{-5}$ & $1.94 \times 10^{-15}$ & $4.94 \times 10^{-5}$ & $4.50 \times 10^{-1}$ \\
\hline S1_K05_C17 & 15 & 19.9 & 1100 & $9.35 \times 10^{-6}$ & $4.47 \times 10^{-11}$ & $9.35 \times 10^{-6}$ & $2.01 \times 10^{-1}$ \\
\hline S1_K05_C27 & 20 & 15 & 850 & $4.95 \times 10^{-5}$ & $2.55 \times 10^{-16}$ & $4.95 \times 10^{-5}$ & $4.49 \times 10^{-1}$ \\
\hline S1_K05_C6 & 18 & 19 & 850 & $4.07 \times 10^{-8}$ & $5.80 \times 10^{-16}$ & $4.07 \times 10^{-8}$ & $2.31 \times 10^{-1}$ \\
\hline S1_K05_C7 & 18 & 19 & 850 & $8.95 \times 10^{-5}$ & $9.05 \times 10^{-5}$ & $1.80 \times 10^{-4}$ & $6.66 \times 10^{-1}$ \\
\hline S1_K08_C1 & 18 & 19 & 850 & $2.47 \times 10^{-6}$ & $3.37 \times 10^{-16}$ & $2.47 \times 10^{-6}$ & $4.64 \times 10^{-1}$ \\
\hline $\mathrm{S} 1 \_\mathrm{K} 08 \_\mathrm{C} 21^{(\mathrm{a})}$ & 18 & 19 & 700 & $6.46 \times 10^{-7}$ & $1.20 \times 10^{-16}$ & $6.46 \times 10^{-7}$ & $1.20 \times 10^{-1}$ \\
\hline S1_K08_C22 & 18 & 19 & 1100 & $4.82 \times 10^{-7}$ & $8.25 \times 10^{-13}$ & $4.82 \times 10^{-7}$ & $2.10 \times 10^{-1}$ \\
\hline S1_K10_C1 & 18 & 19 & 850 & $2.47 \times 10^{-6}$ & $2.06 \times 10^{-16}$ & $2.47 \times 10^{-6}$ & $4.64 \times 10^{-1}$ \\
\hline $\mathrm{S} 1 \_\mathrm{K} 10 \_\mathrm{C} 21^{(\mathrm{a})}$ & 18 & 19 & 700 & $6.46 \times 10^{-7}$ & $8.36 \times 10^{-17}$ & $6.46 \times 10^{-7}$ & $1.20 \times 10^{-1}$ \\
\hline S1_K10_C22 & 18 & 19 & 1100 & $4.82 \times 10^{-7}$ & $4.40 \times 10^{-13}$ & $4.82 \times 10^{-7}$ & $2.10 \times 10^{-1}$ \\
\hline
\end{tabular}

a. Probabilities at $700 \mathrm{~K}$ are slightly under-predicted because the irradiation-induced creep coefficient is expected to be over-estimated at temperatures below $600^{\circ} \mathrm{C}$ therefore over-relaxing the stresses (see Appendix A). 


\section{CONCLUSION}

PARFUME was used to predict the failure probability of UN TRISO fuel in FCM irradiation conditions. From the calculation results, the following conclusions can be drawn:

- The survivability of UN TRISO fuel under LWR irradiation conditions is highly dependent on the values of PyC strain and kernel swelling rates at high fast fluence and burn-up

- PARFUME calculations show that the buffer-IPyC gap closes during irradiation for kernel swelling rates exceeding 1\%/\%FIMA if the PyC exhibits only shrinkage in the tangential direction (PyC strain rates "Set 1")

- The buffer-IPyC gap closes during irradiation for all values of the kernel swelling rate if the PyC exhibits swelling in the tangential direction (PyC strain rates "Set 2")

- The closing of the buffer-IPyC gap is expected to lead to SiC failure

- The internal pressure stays limited in the UN TRISO particle, with maximum values around $3 \mathrm{MPa}$. The potential $\mathrm{SiC}$ failures are triggered by IPyC cracking

- If the buffer-IPyC gap stays open throughout irradiation, PARFUME predicts the highest SiC failure probability to be around $5 \times 10^{-5}$ (with the nominal TRISO geometry)

- The failure probability mostly depends on the irradiation temperature.

- IPyC cracking typically occurs very early during irradiation (around $1 \times 10^{25} \mathrm{n} / \mathrm{m}^{2}$ ), so the fast fluence and burn-up target values do not impact the resulting maximum stresses and subsequent $\mathrm{SiC}$ failure probability.

The conclusions of this study are founded on a fairly weak knowledge of the UN TRISO material properties at high fast fluence and burn-up, and at low temperatures. If the kernel swelling and PyC strain rates are confirmed to have large values at high fast fluence and burn-up, the current design geometry of the UN TRISO particle might not be suitable for LWRs.

One other issue to consider and explore is the interaction between the buffer and the IPyC layer when the buffer-IPyC gap closes. This interaction is not modeled by PARFUME, and any behavior beyond this point is out of the current validity range of the code. Following prior recommendations, it was assumed that a closed gap would lead to a failure of the SiC layer shortly thereafter. Additional mechanical stress calculations would be needed to confirm this assumption. Furthermore, this study did not include the interaction between the TRISO particle and the $\mathrm{SiC}$ matrix that is supposed to surround the fuel in the FCM design. Again, additional calculations could be performed to study how the SiC matrix affects the particle survivability. Another aspect to consider is the role of the $\mathrm{SiC}$ matrix as an additional barrier to fission product diffusion, and how it could affect the acceptable failure probability of the UN TRISO particles.

Aside from calculation refinements, the major uncertainty remains the lack of knowledge of material properties at high fast fluence and burn-up (PyC strain, kernel swelling), and at low temperature (PyC irradiation-induced creep). This issue can only be properly addressed by obtaining experimental data that should focus on reproducing LWR irradiation conditions (fast fluence, burn-up, and temperature) on a UN TRISO fuel nominal design. Only the combination of these experimental data with a refined model of the fuel behavior and performance in a LWR environment will guarantee the applicability of FCM fuel to LWRs. 
However, results from stress calculations show that high fast fluence and burn-up values have no impact on the particle failure probability when the buffer-IPyC gap remains open because IPyC cracking occurs early during irradiation and there is no contribution from internal pressure at the low LWR temperatures. This is only the case if both kernel swelling and PyC strain are limited at high fast fluence and burn-up, which is highly uncertain. The main issue for UN TRISO fuel is therefore mostly the evolution of the width of the buffer-IPyC gap, which is determined by the kernel swelling and PyC strain at high fast flence and burn-up. The irradiation-induced creep of the $\mathrm{PyC}$ at low temperature might also be a factor as it directly impacts the relief of the stress in the IPyC layer, with a subsequent impact on particle failure. In addition, the fracture strength of the IPyC layer at high fast fluence is assumed to remain constant and equal to its value at the cut-off fluence of $4 \times 10^{25} \mathrm{n} / \mathrm{m}^{2}$, while the fracture strength of the $\mathrm{SiC}$ layer is assumed to be constant over the whole range of fast fluence. Even with an open bufferIPyC gap throughout irradiation, the particle failure probability would be negatively affected should these strengths degrade at very high fast fluences. 


\section{REFERENCES}

Abaqus/Standard, “Abaqus User's Manual,” Version 6.7, 2007.

American Society of Mechanical Engineers, "NQA-1-2008; 1a-2009 Quality Assurance Requirements for Nuclear Facility Applications," March 14, 2008 (Addenda August 31, 2009).

A. H. Booth, "A Method of Calculating Fission Gas Diffusion from $\mathrm{UO}_{2}$ Fuel and Its Application to the X-2-f Loop Test," CRDC-721, Atomic Energy of Canada Limited Report 496, September 1957.

CEGA Corporation, "NP-MHTGR Material Models of Pyrocarbon and Pyrolytic Silicon Carbide," CEGA-002820, Rev. 1, July 1993.

P. DeMange, J. Marian, M. Caro, A. Caro, "TRISO-fuel element thermo-mechanical performance modeling for the hybrid LIFE engine with Pu fuel blanket," Journal of Nuclear Materials 405 (2010) 144-155, August 2010.

IAEA, "Development status of metallic, dispersion and non-oxide advanced and alternative fuels for power and research reactors," International Atomic Energy Agency, Tecdoc-1374, September 2003.

D. G. Martin, "Considerations pertaining to the achievement of high burn-ups in HTR fuel," Nuclear Engineering and Design 213 (2002) 241-258.

G. K. Miller, D. C. Wadsworth, "Treating asphericity in fuel particle pressure vessel modeling," Journal of Nuclear Materials 211 (1994) 57-69, March 1994.

G. K. Miller, D. A. Petti, D. J. Varacalle, J. T. Maki, "Statistical approach and benchmarking for modeling of multi-dimensional behavior in TRISO-coated fuel particles," Journal of Nuclear Materials 317 (2003) 69-82, December 2002.

G. K. Miller, D. A. Petti, J. T. Maki, D. L. Knudson, "An evaluation of the effects of SiC layer thinning on failure of TRISO-coated fuel particles," Journal of Nuclear Materials 355 (2006) 150-162, May 2006.

G. K. Miller, D. A. Petti, J. T. Maki, D. L. Knudson, "PARFUME Theory and Model Basis Report," INL/EXT-08-14497, September 2009.

L. C. Northcliffe, R. F. Schilling, "Range and Stopping - Power Tables for Heavy Ions," Nuclear Data Tables, A7, 233-463, 1970.

D. A. Petti, P. Martin, M. Phelip, R. Balinger, "Development of Improved Models and Designs for Coated-Particle Gas Reactor Fuels," INEEL/EXT-05-02615, December 2004.

S. R. Ross, M. S. El-Glenk, R. B. Matthews, "Thermal conductivity correlation for uranium nitride fuel between 10 and 1923 K," Journal of Nuclear Materials 151 (1988) 313-317, September 1987.

J. Simonds, "Technical Program Plan for the Very High Temperature Reactor Technology Development Office / Advanced Gas Reactor Fuel Development and Qualification Program," PLN-3636, Rev. 2, December 18, 2012.

L. L. Snead, et al. "Handbook of siC properties for fuel performance modeling," Journal of Nuclear Materials 371 (2007) 329-377, May 2007.

E. K. Storms, "An equation which describes fission gas release from UN reactor fuel," Journal of Nuclear Materials 158 (1988) 119-129, March 1988.

K. A. Terrani, L. L. Snead, J. C. Gehin, "Microencapsulated fuel technology for commercial light water and advanced reactor application," Journal of Nuclear Materials 427 (2012) 209-224, May 2012. 
C. Wise, "Recoil release of fission products from nuclear fuel," Journal of Nuclear Materials 136 (1985) 30-47, June 1985. 
Appendix A

Material Properties 


\section{Appendix A \\ Material Properties}

Thermal conductivity

\section{UN kernel}

The un-irradiated thermal conductivity $\left(\lambda_{0}\right)$ is obtained from (Ross 1988):

$$
\lambda_{0}=1.37 * \mathrm{~T}^{0.41} * \frac{1-\mathrm{p}}{1+\mathrm{p}} \quad(\mathrm{W} / \mathrm{m}-\mathrm{K})
$$

with $\mathrm{T}$ temperature $(\mathrm{K})$

$$
\mathrm{p} \quad \text { kernel porosity }
$$

A burn-up correction is applied to the un-irradiated thermal conductivity to take into account its decrease with irradiation:

$$
\lambda=\lambda_{0} *(1-0.025 * \mathrm{BU}) \quad(\mathrm{W} / \mathrm{m}-\mathrm{K})
$$

with BU burn-up (\%FIMA)

The value 0.025 is derived from the drop in thermal conductivity with burn-up observed for $\mathrm{UO}_{2}$ in (Petti 2004) and displayed below:

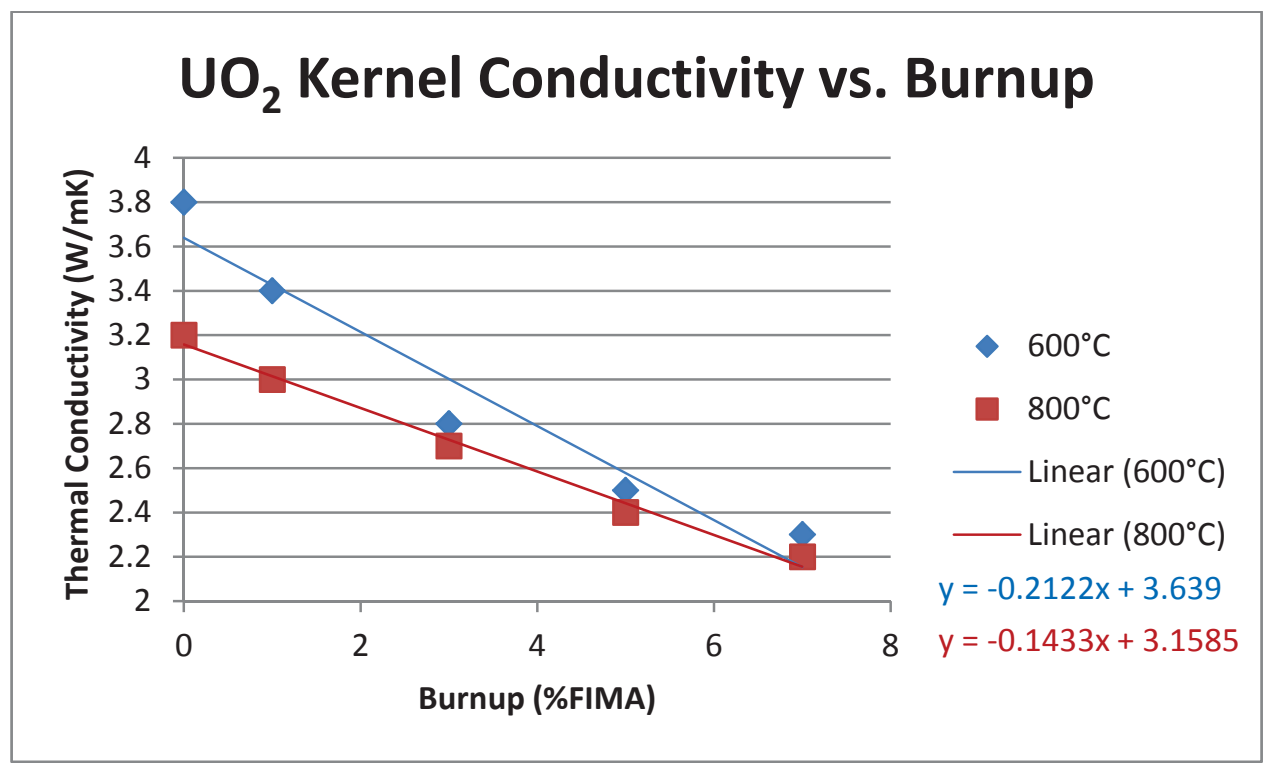

The conductivity can be fitted as $\lambda=\mathrm{a} * \mathrm{BU}+\lambda_{0}$ To match the expression $\lambda=\lambda_{0} *(1-\alpha * \mathrm{BU})$, the following relation has to be established: $\alpha=-\mathrm{a} / \lambda_{0}$.

For the two trends at 600 and $800^{\circ} \mathrm{C}$, this would respectively give $\alpha=0.058$ and $\alpha=0.045$, both of which would lead to very low thermal conductivities at high burn-up which, although it is being unknown, is not so likely. A value of $\alpha=0.025$ was then used to limit the thermal conductivity drop at high burn-up. 


\section{$\underline{\text { Buffer } / \mathrm{PyC} / \mathrm{SiC}}$}

The thermal conductivities $(\lambda)$ recommended by PARFUME were used (Miller 2009):

- Buffer: $\quad \lambda=0.5 \quad(\mathrm{~W} / \mathrm{m}-\mathrm{K})$

- PyC: $\lambda=4 \quad(\mathrm{~W} / \mathrm{m}-\mathrm{K})$

- $\mathrm{SiC}: \quad \lambda=\frac{17885}{\mathrm{~T}}+2 \quad(\mathrm{~W} / \mathrm{m}-\mathrm{K})$

with $\mathrm{T}$ temperature $(\mathrm{K})$

Thermal expansion

Buffer / PyC

The coefficients of thermal expansion $(\alpha)$ recommended by PARFUME were used (Miller 2009):

- $\quad$ PyC - Radial

$$
\begin{aligned}
& \alpha=\left(1+0.11 \frac{\mathrm{T}-673}{700}\right) *\left(30-\frac{75}{2+\mathrm{BAF}}\right) \quad\left(10^{-6} \mathrm{~K}^{-1}\right) \\
& \text { - } \quad \text { PyC }- \text { Tangential } \alpha=\left(1+0.11 \frac{\mathrm{T}-673}{700}\right) *\left(1+\frac{36}{(2+\mathrm{BAF})^{2}}\right) \quad\left(10^{-6} \mathrm{~K}^{-1}\right) \\
& \alpha=\left(1+0.11 \frac{\mathrm{T}-673}{700}\right) * 5 \\
& \left(10^{-6} \mathrm{~K}^{-1}\right)
\end{aligned}
$$

- Buffer

with $\mathrm{T}$ temperature $(\mathrm{K})$

BAF Bacon Anisotropy Factor

$\underline{\mathrm{SiC}}$

The coefficient of thermal expansion $(\alpha)$ is taken from (Snead 2007):

For $\mathrm{T}<1273 \mathrm{~K}$

$$
\alpha=-1.8276+0.0178 * \mathrm{~T}-1.5544 \times 10^{-5} * \mathrm{~T}^{2}+4.5246 \times 10^{-9} * \mathrm{~T}^{3}\left(10^{-6} \mathrm{~K}^{-1}\right)
$$

For $\mathrm{T}>1273 \mathrm{~K}$

$$
\alpha=5.0 \quad\left(10^{-6} \mathrm{~K}^{-1}\right)
$$

The plot below shows how this coefficient compares to the default PARFUME setting.

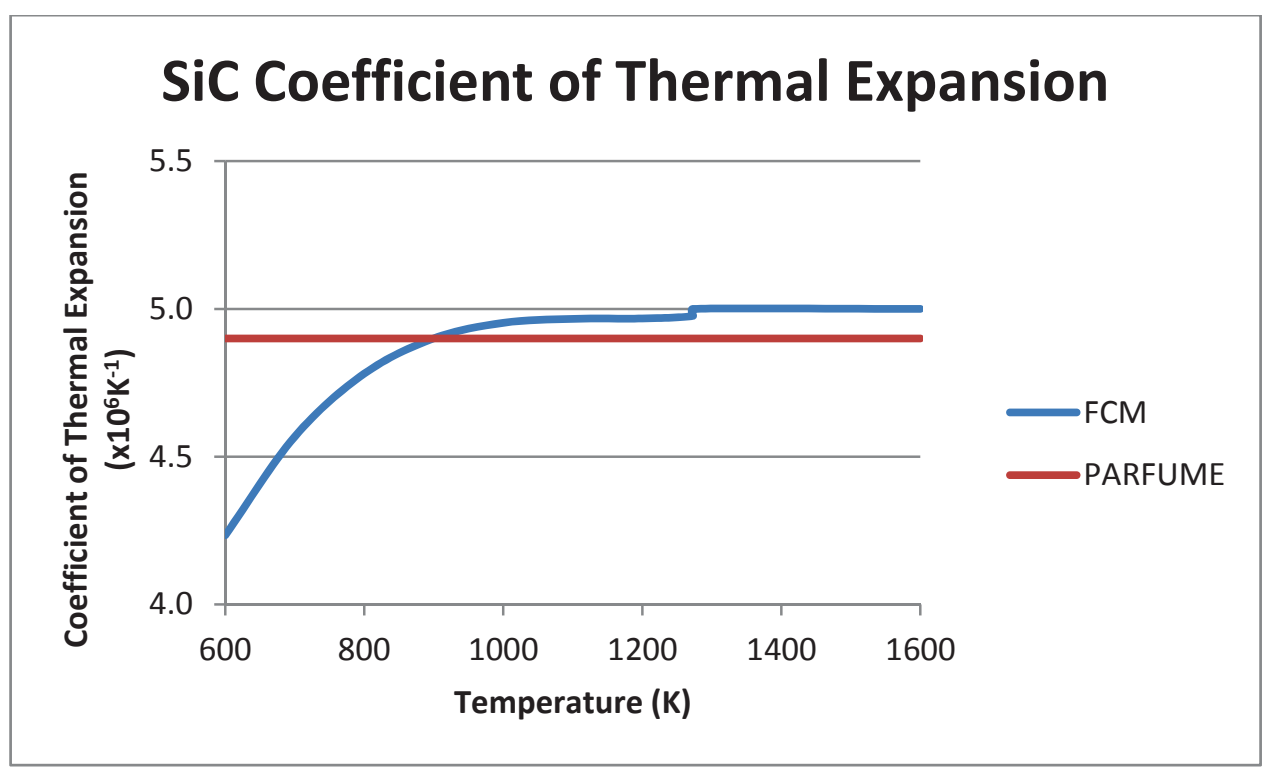




\section{Modulus of elasticity}

$\underline{P y C}$

The modulus of elasticity (E) recommended by PARFUME was used (Miller 2009):

$\mathrm{E}=\mathrm{E}\left(\rho, \mathrm{BAF}, \mathrm{L}_{\mathrm{c}}, \Phi, \mathrm{T}\right)$ (see (Miller 2009) for variation of modulus of elasticity with parameters)

with $\rho \quad$ density $\left(\mathrm{g} / \mathrm{cm}^{3}\right)$

BAF Bacon Anisotropy Factor

$\mathrm{L}_{\mathrm{c}} \quad$ crystallite diameter $(\AA)$

$\Phi$ fast fluence $\left(\times 10^{25} \mathrm{n} / \mathrm{m}^{2}\right)$

$\mathrm{T}$ temperature $(\mathrm{K})$

The modulus of elasticity exhibits a fast fluence dependence expressed by the factor $(1+0.23 \times \Phi)$. Beyond the cut-off fast fluence of $4 \times 10^{25} \mathrm{n} / \mathrm{m}^{2}$ this correction factor is set equal to its cut-off value (1.9108).

$\underline{\mathrm{SiC}}$

The modulus of elasticity (E) is taken from (Snead 2007):

$$
\mathrm{E}=460 * \mathrm{e}^{-3.57 * \mathrm{p}}-0.04 * \mathrm{~T} * \mathrm{e}^{-962 / \mathrm{T}} \quad(\mathrm{GPa})
$$

with $\quad \mathrm{p} \quad \mathrm{SiC}$ porosity

$\mathrm{T}$ temperature $(\mathrm{K})$

The porosity of the $\mathrm{SiC}$ is not a parameter in PARFUME. Its value depends on the relative values of the fabricated and theoretical SiC densities. In the current fabrication process of US TRISO fuel the porosity is well below $1 \%$. It is taken equal to 0 in this study.

The plot below shows how this modulus of elasticity compares to the default PARFUME setting.

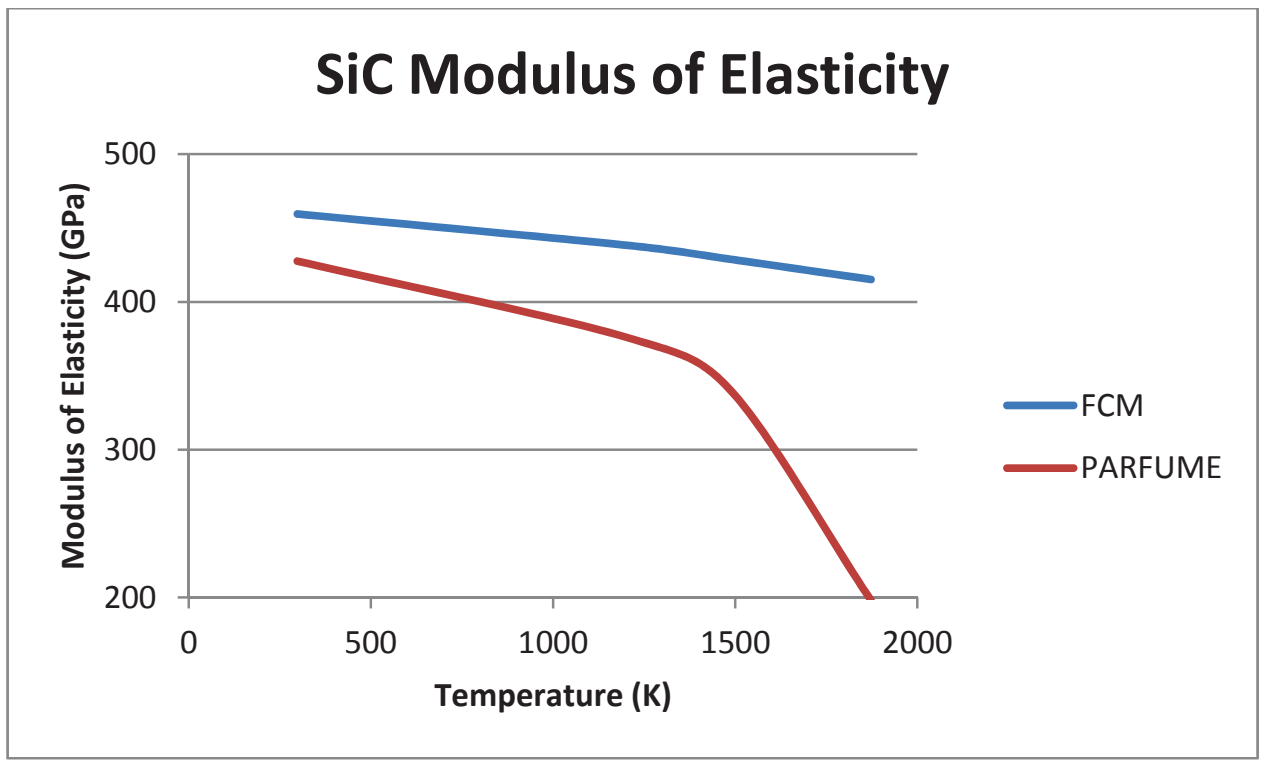




\section{$\underline{\text { Irradiation-induced dimensional change }}$}

The irradiation-induced dimensional changes for PyC are not known at high fast fluence. PARFUME strain rates are extrapolated beyond a cut-off value of $4 \times 10^{25} \mathrm{n} / \mathrm{m}^{2}$, with no guarantee to represent the real behavior of highly irradiated PyC. To better assess the behavior of $\mathrm{PyC}$ at high fast fluence, a second set of strain rates was used in addition to PARFUME default strain rates. The buffer strain rates rely on PARFUME only.

\section{Buffer / PyC (Set 1)}

The strain rates $(\dot{\varepsilon})$ recommended by PARFUME were used in Set 1 (Miller 2009):

$$
\dot{\varepsilon}=\dot{\varepsilon}(\mathrm{T}, \Phi, \rho, \mathrm{BAF}) \quad \text { (see (Miller 2009) for variation of strain rate with parameters) }
$$

with $\mathrm{T}$ temperature $(\mathrm{K})$

$\Phi \quad$ fast fluence $\left(\times 10^{25} \mathrm{n} / \mathrm{m}^{2}\right)$

$\rho \quad$ density $\left(\mathrm{g} / \mathrm{cm}^{3}\right)$

BAF Bacon Anisotropy Factor

Beyond the cut-off fast fluence of $4 \times 10^{25} \mathrm{n} / \mathrm{m}^{2}$, the computation of the strain rate assumes a value of the fast fluence equal to the cut-off value of $4 \times 10^{25} \mathrm{n} / \mathrm{m}^{2}$.

\section{PyC (Set 2)}

The strain rates of Set 2 were obtained from (DeMange 2010):

- Radial strain rate $(\%)$

$$
\begin{array}{ll}
\dot{\varepsilon_{\mathrm{r}}}=-1.044+0.306 * \Phi & \text { at } 600^{\circ} \mathrm{C} \\
\dot{\varepsilon_{\mathrm{r}}}=-1.145+0.560 * \Phi & \text { at } 1050^{\circ} \mathrm{C}
\end{array}
$$

- $\quad$ Tangential strain rate $(\%)$

$$
\begin{array}{ll}
\dot{\varepsilon_{\mathrm{t}}}=-1.276+0.282 * \Phi & \text { at } 600^{\circ} \mathrm{C} \\
\dot{\varepsilon_{\mathrm{t}}}=-1.493+0.278 * \Phi & \text { at } 1050^{\circ} \mathrm{C}
\end{array}
$$

with $\Phi$ fast fluence $\left(\times 10^{25} \mathrm{n} / \mathrm{m}^{2}\right)$

Strain rates at other temperatures are obtained by inter/extrapolations.

The plots below illustrate the fast fluence dependence of both sets of radial and tangential strains. FCM values (Set 2) were obtained for a PyC density of $1.85 \mathrm{~g} / \mathrm{cm}^{3}$ and a BAF value of 1.036 at temperatures of 600 and $1050^{\circ} \mathrm{C}$, while PARFUME values (Set 1) were obtained for a PyC density of $1.96 \mathrm{~g} / \mathrm{cm}^{3}$ and BAF values of 1.035 radially and 1.030 tangentially at temperatures of 600 and $1032^{\circ} \mathrm{C}$. 

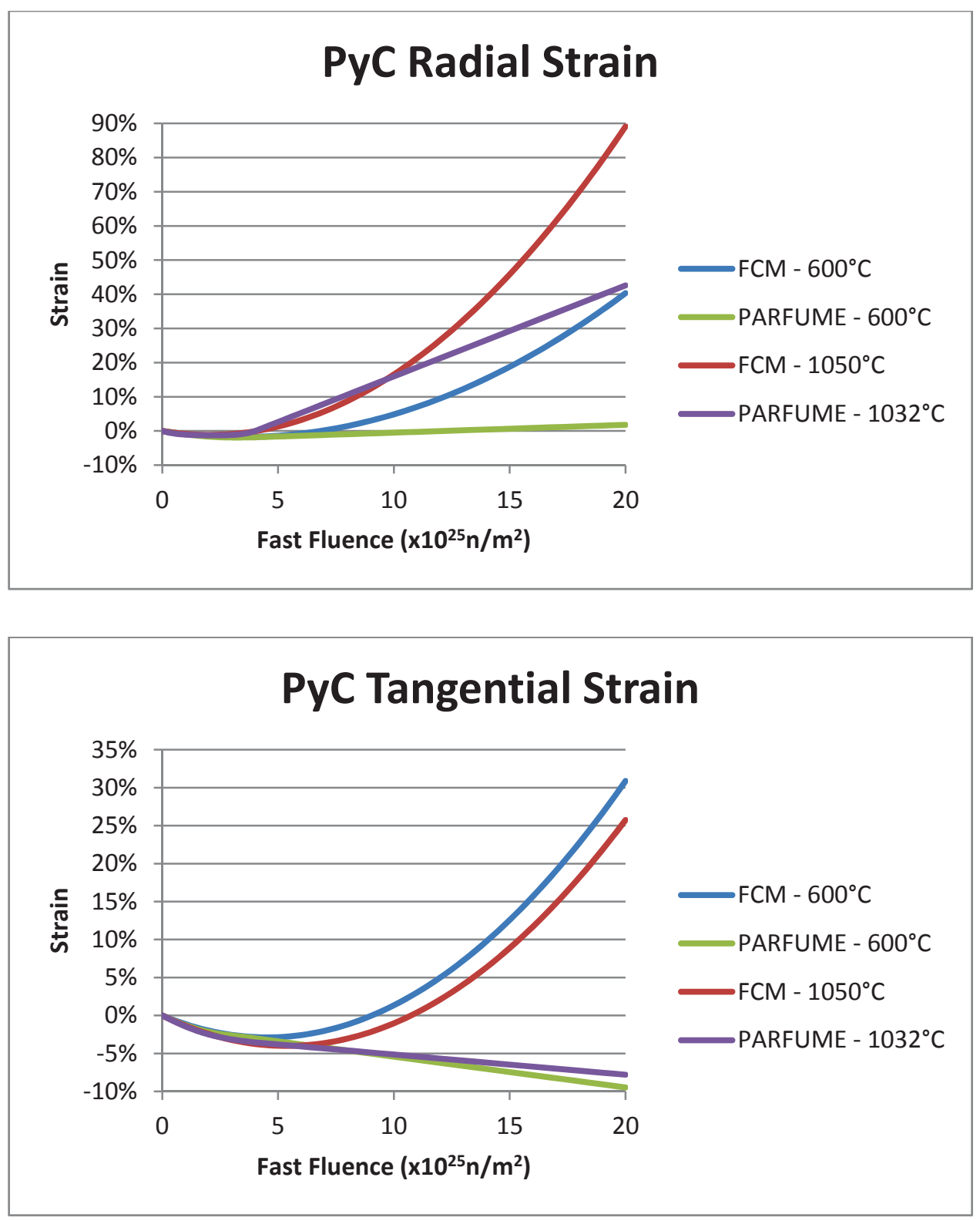


\section{Irradiation-induced creep}

\section{Buffer / PyC}

The irradiation-induced creep coefficient $\left(\mathrm{K}_{\mathrm{S}}\right)$ recommended by PARFUME was (Miller 2009):

$$
\begin{aligned}
& \mathrm{K}_{\mathrm{S}}=2 *(1+2.38 *(1.9-\rho)) *\left(2.193 * 10^{-4}-4.85 * 10^{-7} * \mathrm{~T}+4.0147 * 10^{-10} * \mathrm{~T}^{2}\right) \\
& \left(10^{-25}\left(\mathrm{MPa}-\mathrm{n} / \mathrm{m}^{2}\right)^{-1}\right)
\end{aligned}
$$

$\begin{array}{lll}\text { with } & \mathrm{T} & \text { temperature }\left({ }^{\circ} \mathrm{C}\right) \\ & \rho & \text { density }\left(\mathrm{g} / \mathrm{cm}^{3}\right)\end{array}$

The plot below shows the temperature component $\mathrm{K}_{\mathrm{S} 0}$ :

$$
\mathrm{K}_{\mathrm{S} 0}=2.193 * 10^{-4}-4.85 * 10^{-7} * \mathrm{~T}+4.0147 * 10^{-10} * \mathrm{~T}^{2}
$$

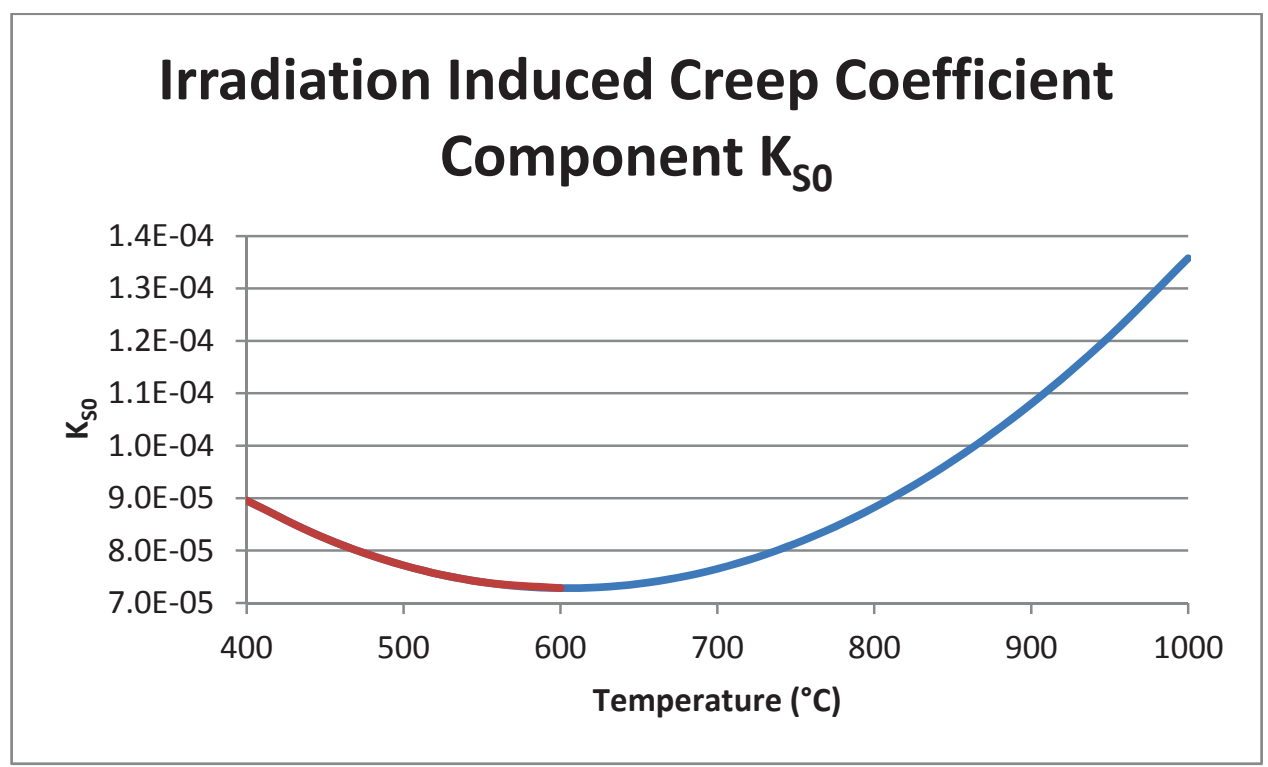

It was obtained by fitting data between 600 and $1200^{\circ} \mathrm{C}$ (CEGA 1993) and it is expected to not be valid at temperatures below $600^{\circ} \mathrm{C}$. 


\section{Weibull parameters}

$\underline{\text { PyC }}$

The characteristic strength $\left(\sigma_{0}\right)$ and Weibull modulus $(\mathrm{m})$ recommended by PARFUME were used (Miller 2009):

- $\sigma_{0}=\sigma_{0}\left(\mathrm{~T}, \mathrm{~T}_{\mathrm{r}} \Phi, \mathrm{BAF}_{0}\right)$

- $\mathrm{m}=9.5$

with $\mathrm{T}$ temperature $(\mathrm{K})$

$\mathrm{T}_{\mathrm{r}} \quad$ room temperature $(\mathrm{K})$

$\Phi \quad$ fast fluence $\left(\times 10^{25} \mathrm{n} / \mathrm{m}^{2}\right)$

$\mathrm{BAF}_{0}$ unirradiated value of the Bacon Anisotropy Factor

The characteristic strength exhibits a fast fluence dependence expressed by the factor $(1+0.23 \times \Phi)^{1 / 2}$. Beyond the cut-off fast fluence of $4 \times 10^{25} \mathrm{n} / \mathrm{m}^{2}$, this correction factor is set equal to its cut-off value (1.3823).

$\underline{\mathrm{SiC}}$

The characteristic strength $\left(\sigma_{0}\right)$ and Weibull modulus $(\mathrm{m})$ recommended by PARFUME were used (Miller 2009):

- $\sigma_{0}=9.64 \quad\left(\mathrm{MPa}-\mathrm{m}^{-3 / 6}\right)$

- $\mathrm{m}=6$

\section{Fission gas release}

Only Krypton and Xenon are considered as released gas. Other fission product species, such as Cesium, are expected to form gaseous compounds but the lack of chemistry knowledge associated to UN fuel prompts to not incorporating them in the fission gas release calculation. Lighter species, such as Helium or Hydrogen, can be produced in ternary fissions and/or by alpha decay but the production rate is low compared to these of $\mathrm{Kr}$ and $\mathrm{Xe}$.

\section{$\underline{\text { Recoil release }}$}

The recoil release fraction was calculated by PARFUME using the following average recoil ranges for $\mathrm{Kr}$ and $\mathrm{Xe}$ in $\mathrm{UN}$ :

- Kr range: $5.68 \mu \mathrm{m}$

- Xe range: $3.98 \mu \mathrm{m}$

These values were derived following the methodology established by C. Wise (Wise 1985), and using Northcliffe and Schilling's nuclear data tables (Northcliffe 1970). Since UN is not part of the materials listed in the tables, a material with the same mean average atomic number was used, namely silver.

\section{Diffusive release}

The diffusive release fraction was calculated according to the Booth equivalent sphere diffusion model (Booth 1957) using the effective diffusion coefficient $D_{\mathrm{g}}\left(\mathrm{cm}^{-2} \cdot \mathrm{s}^{-1}\right)$ defined as:

$$
D_{g}=6.6454 * 10^{-12} * \mathrm{e}^{-19164 / \mathrm{T}}
$$

with $\mathrm{T}$ temperature $(\mathrm{K})$

This diffusion coefficient was obtained from fission gas release data from UN reactor fuel presented in the figure below (Storms 1988). For each data point, the Booth model was applied to derive a corresponding diffusion coefficient. All the individual diffusion coefficients were then fitted to calculate 
the effective diffusion coefficient. The release data was obtained for a range of average fuel temperatures of $1300-1850 \mathrm{~K}$, which is higher than the range of operating temperatures considered in this study. The diffusive release is therefore calculated by extrapolating the effective diffusion coefficient to temperatures lower than its validity range.
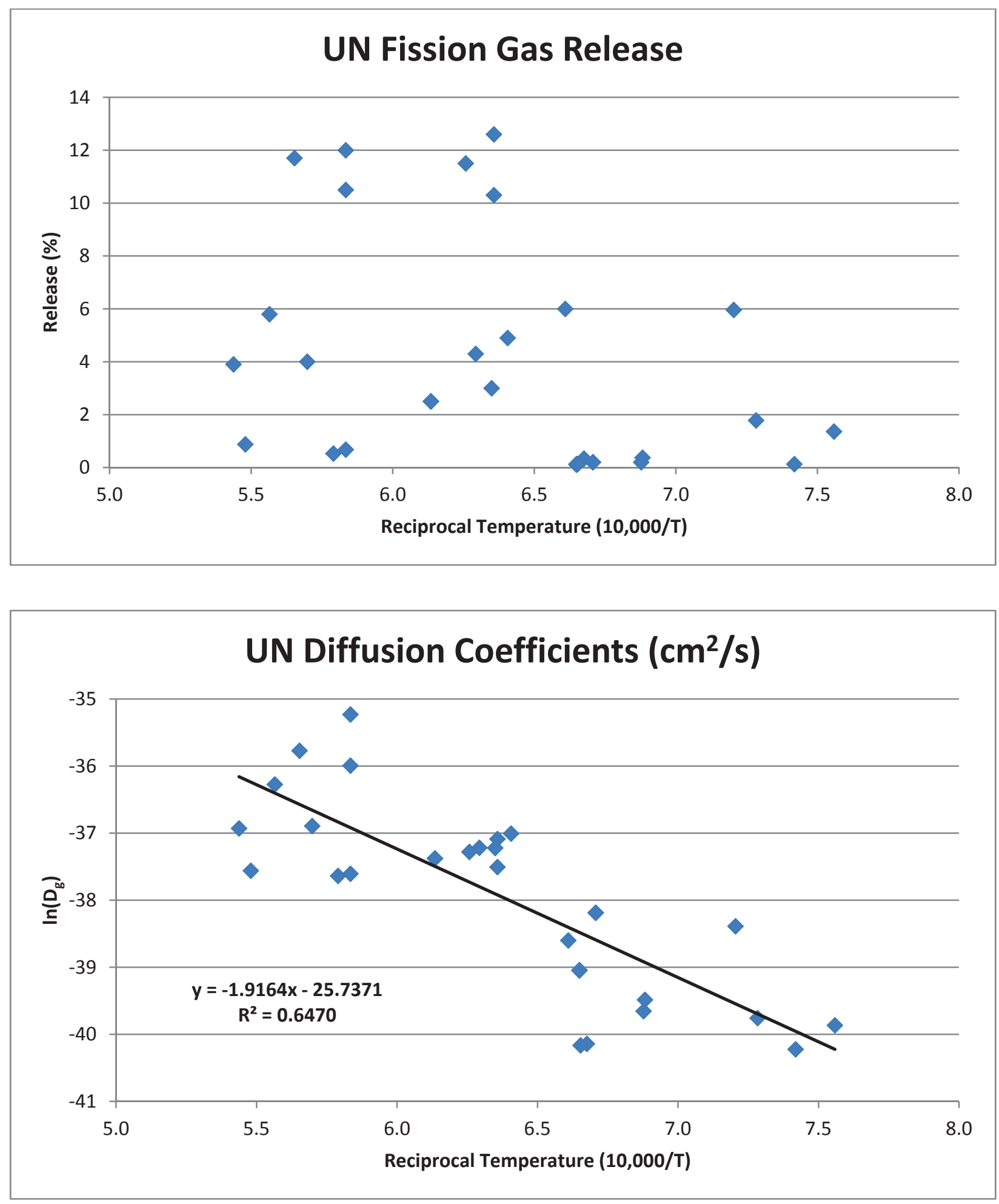
Appendix B Study Cases 


\section{Appendix B Study Cases}

\begin{tabular}{|c|c|c|c|c|c|c|c|c|c|c|c|c|}
\hline \multirow{4}{*}{ Case } & \multicolumn{12}{|c|}{ Kernel Swelling Rate (/\%FIMA) } \\
\hline & \multicolumn{2}{|c|}{$0.5 \%$} & \multicolumn{2}{|c|}{$0.8 \%$} & \multicolumn{2}{|c|}{$1.0 \%$} & \multicolumn{2}{|c|}{$1.2 \%$} & \multicolumn{2}{|c|}{$1.5 \%$} & \multicolumn{2}{|c|}{$2.0 \%$} \\
\hline & \multicolumn{2}{|c|}{ PyC Strain } & \multicolumn{2}{|c|}{ PyC Strain } & \multicolumn{2}{|c|}{ PyC Strain } & \multicolumn{2}{|c|}{ PyC Strain } & \multicolumn{2}{|c|}{ PyC Strain } & \multicolumn{2}{|c|}{ PyC Strain } \\
\hline & Set 1 & Set 2 & Set 1 & Set 2 & Set 1 & Set 2 & Set 1 & Set 2 & Set 1 & Set 2 & Set 1 & Set 2 \\
\hline \multicolumn{13}{|l|}{ Nom-1 } \\
\hline \multicolumn{13}{|l|}{ Sto-2 } \\
\hline \multicolumn{13}{|l|}{ Buf-3 } \\
\hline \multicolumn{13}{|l|}{ Buf-4 } \\
\hline \multicolumn{13}{|l|}{ Buf-5 } \\
\hline \multicolumn{13}{|l|}{ PyC-6 } \\
\hline \multicolumn{13}{|l|}{ PyC-7 } \\
\hline \multicolumn{13}{|l|}{ Den-8 } \\
\hline \multicolumn{13}{|l|}{ Par-9 } \\
\hline \multicolumn{13}{|l|}{ Par-10 } \\
\hline Par-11 & & & & & & & & & & & & \\
\hline Par-12 & & & & & & & & & & & & \\
\hline Par-13 & & & & & & & & & & & & \\
\hline Par-14 & & & & & & & & & & & & \\
\hline Par-15 & & & & & & & & & & & & \\
\hline Par-16 & & & & & & & & & & & & \\
\hline Par-17 & & & & & & & & & & & & \\
\hline Par-18 & & & & & & & & & & & & \\
\hline Par-19 & & & & & & & & & & & & \\
\hline Par-20 & & & & & & & & & & & & \\
\hline Par-21 & & & & & & & & & & & & \\
\hline Par-22 & & & & & & & & & & & & \\
\hline Par-23 & & & & & & & & & & & & \\
\hline Par-24 & & & & & & & & & & & & \\
\hline Par-25 & & & & & & & & & & & & \\
\hline Par-26 & & & & & & & & & & & & \\
\hline Par-27 & & & & & & & & & & & & \\
\hline Par-28 & & & & & & & & & & & & \\
\hline Par-29 & & & & & & & & & & & & \\
\hline Par-30 & & & & & & & & & & & & \\
\hline Par-31 & & & & & & & & & & & & \\
\hline Par-32 & & & & & & & & & & & & \\
\hline Par-33 & & & & & & & & & & & & \\
\hline Par-34 & & & & & & & & & & & & \\
\hline
\end{tabular}

calculation passed / calculation requires 100- $\mu \mathrm{m}$ buffer / calculation failed 


\section{Appendix C \\ Irradiation Limits}




\section{Appendix C \\ Irradiation Limits}

Maximum fast fluence and burn-up values that could be achieved depending on the prospective irradiation target values. All plots were obtained using an $880-\mu \mathrm{m}$ diameter kernel coated with a $60-\mu \mathrm{m}$ thick buffer.
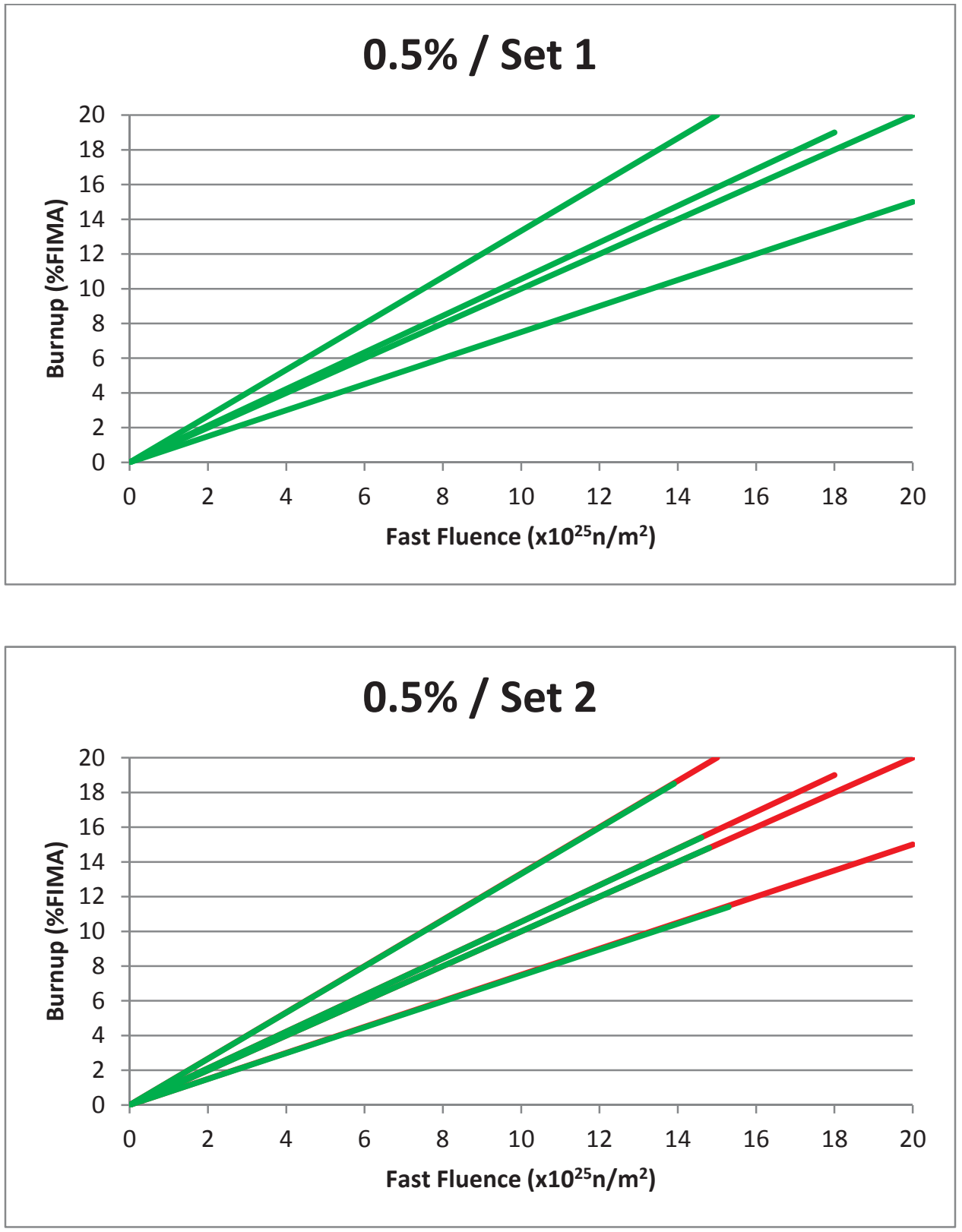

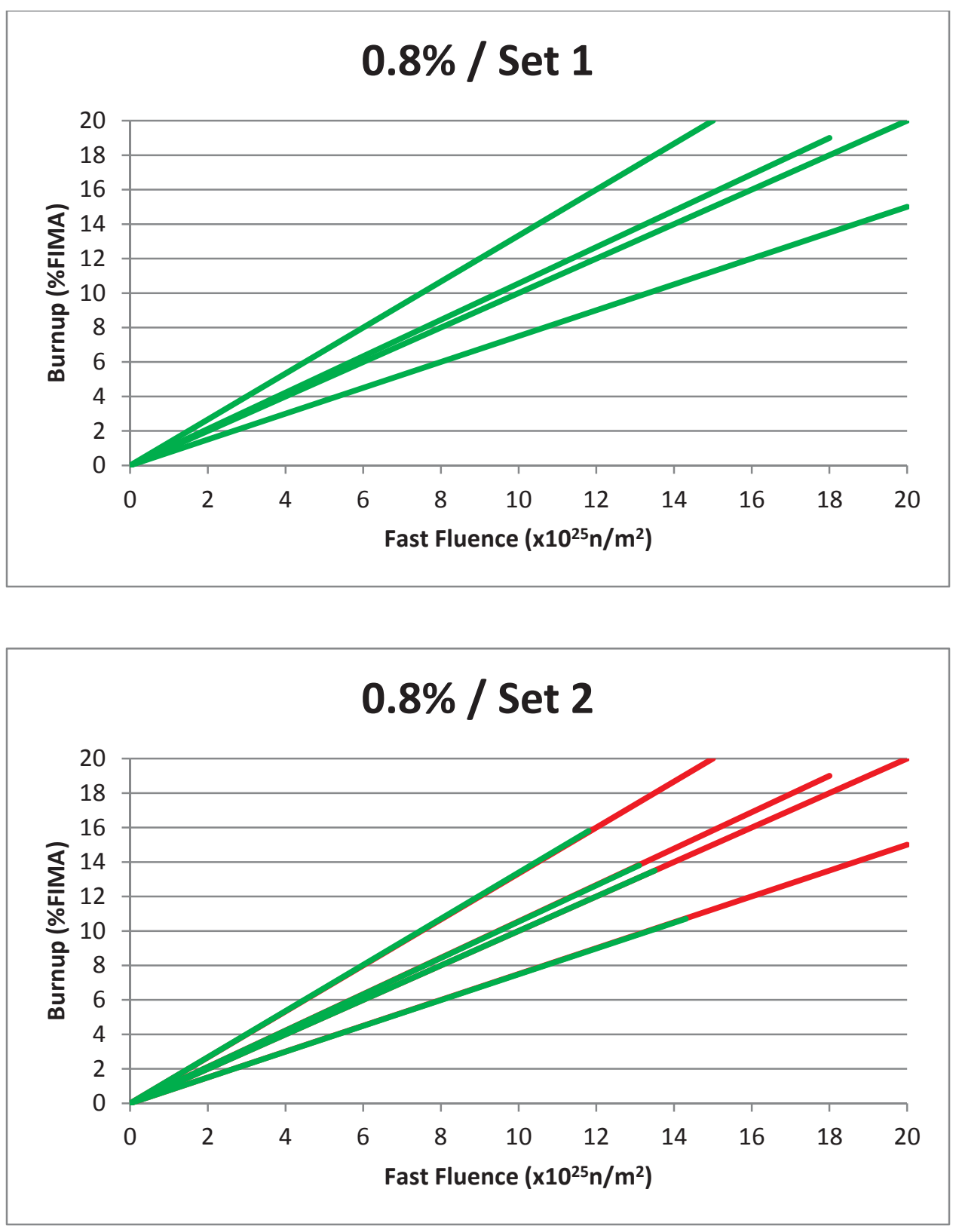

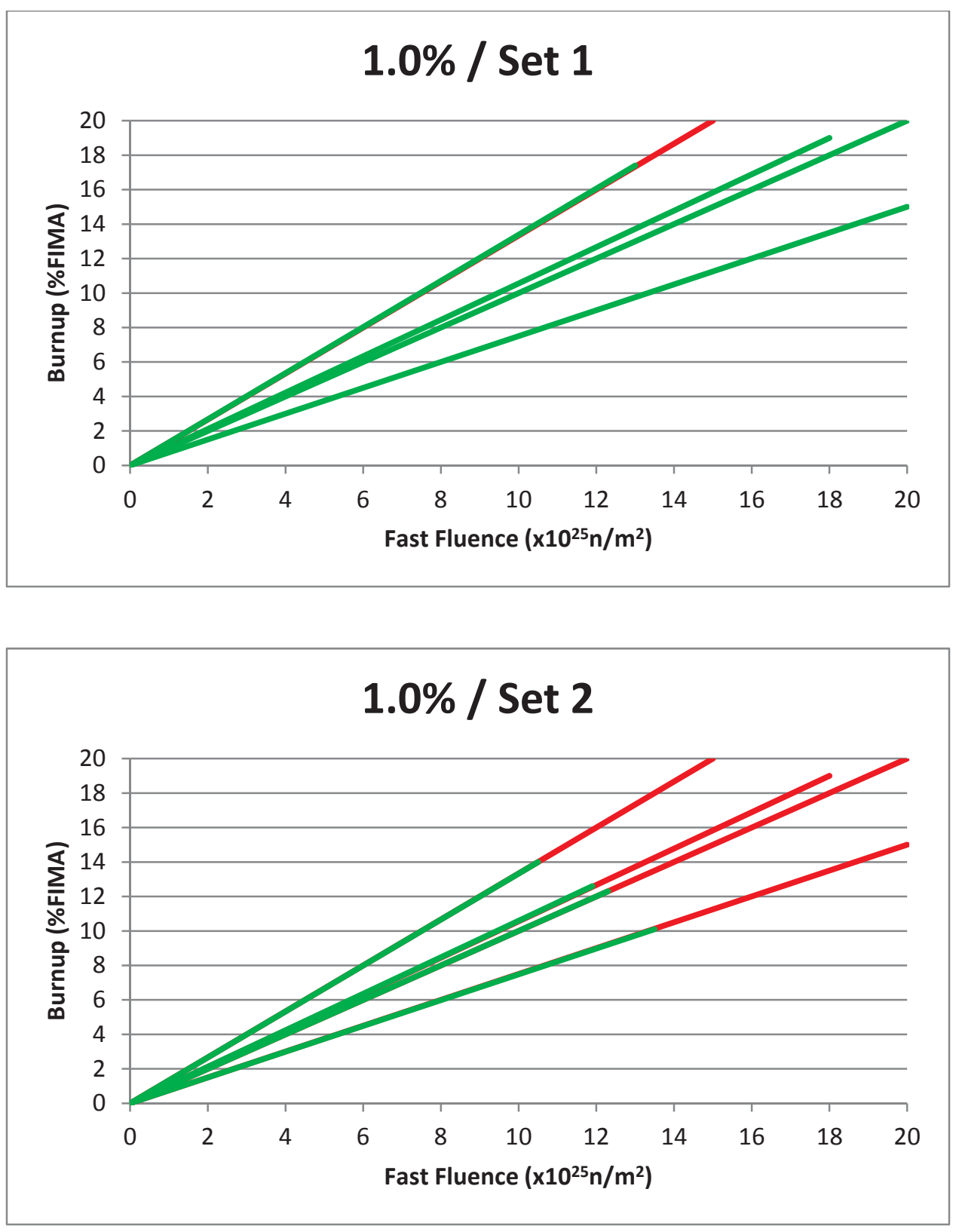

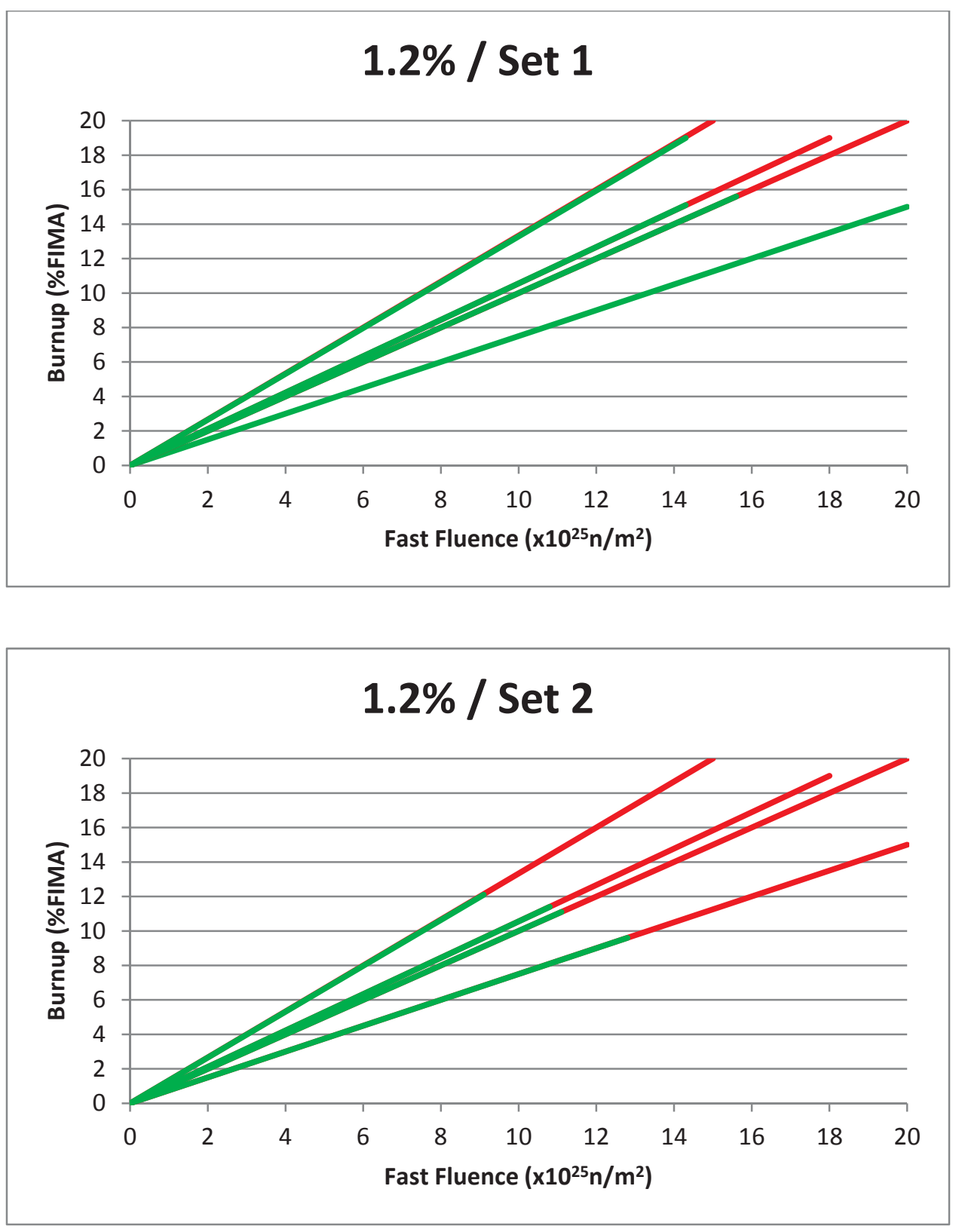

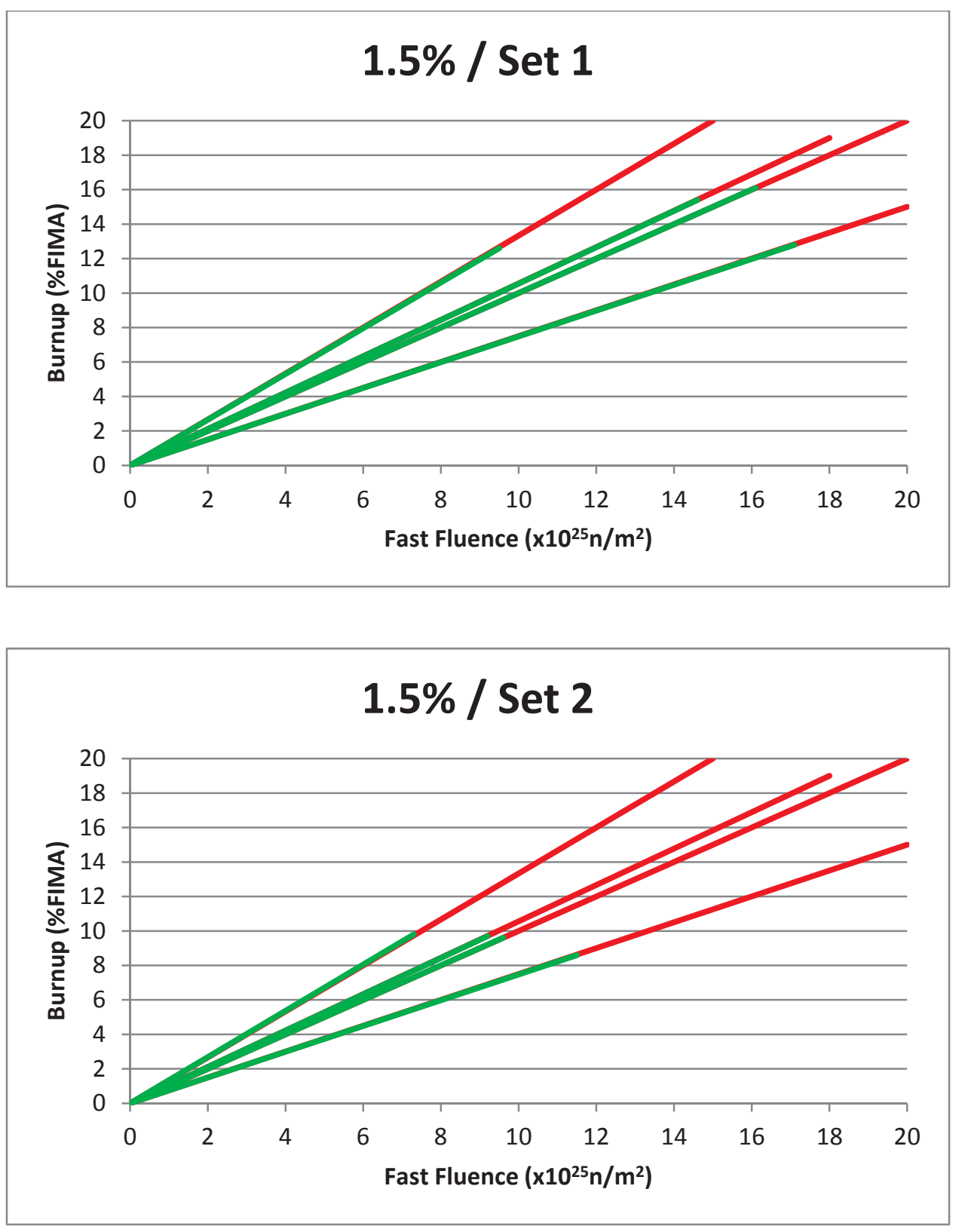

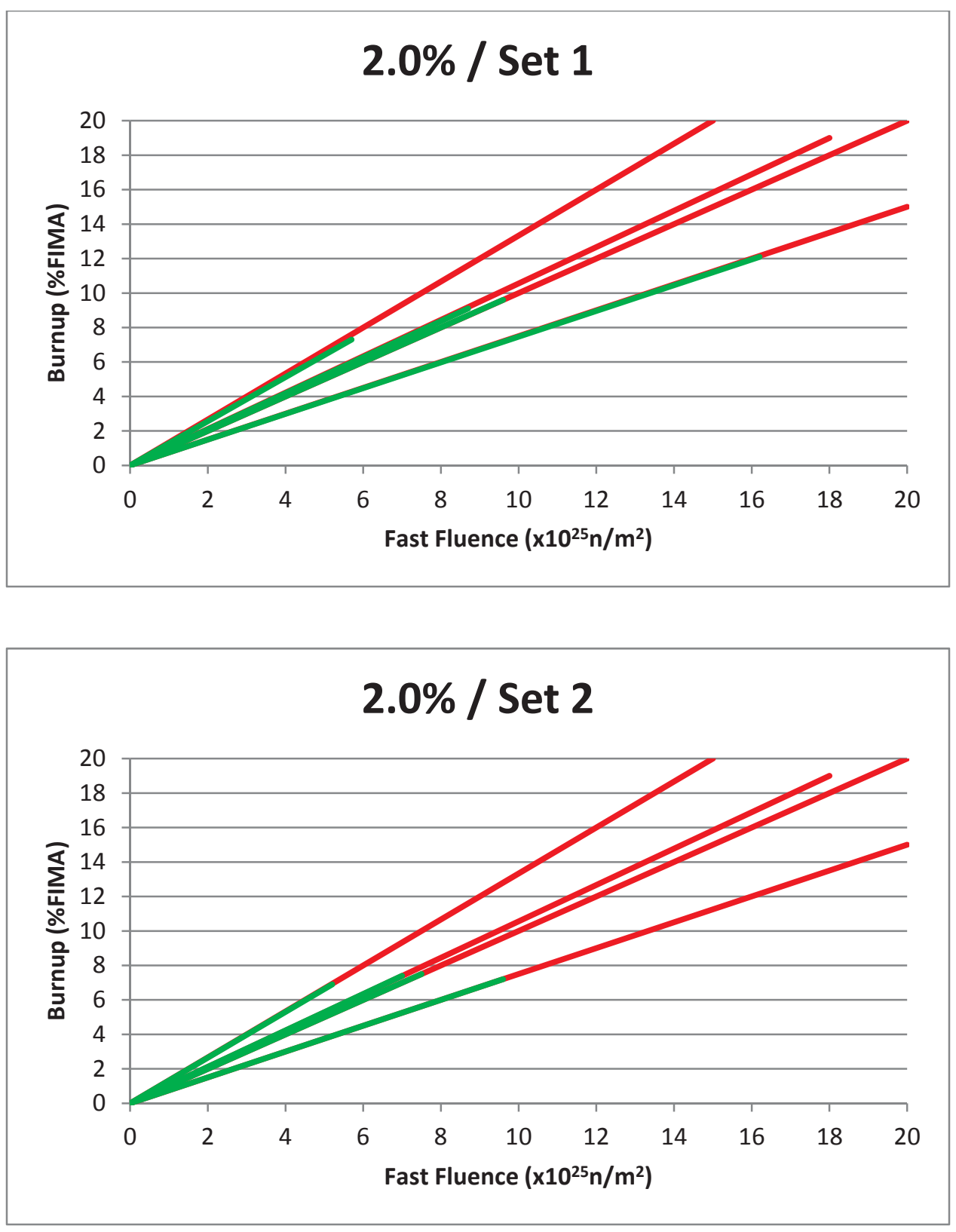


\section{Appendix D \\ PARFUME Input Deck}




\section{Appendix D PARFUME Input Deck}

Highlighted values are specific to the fuel geometry.

Italic values are specific to the fuel properties.

Bold values are specific to the irradiation conditions.

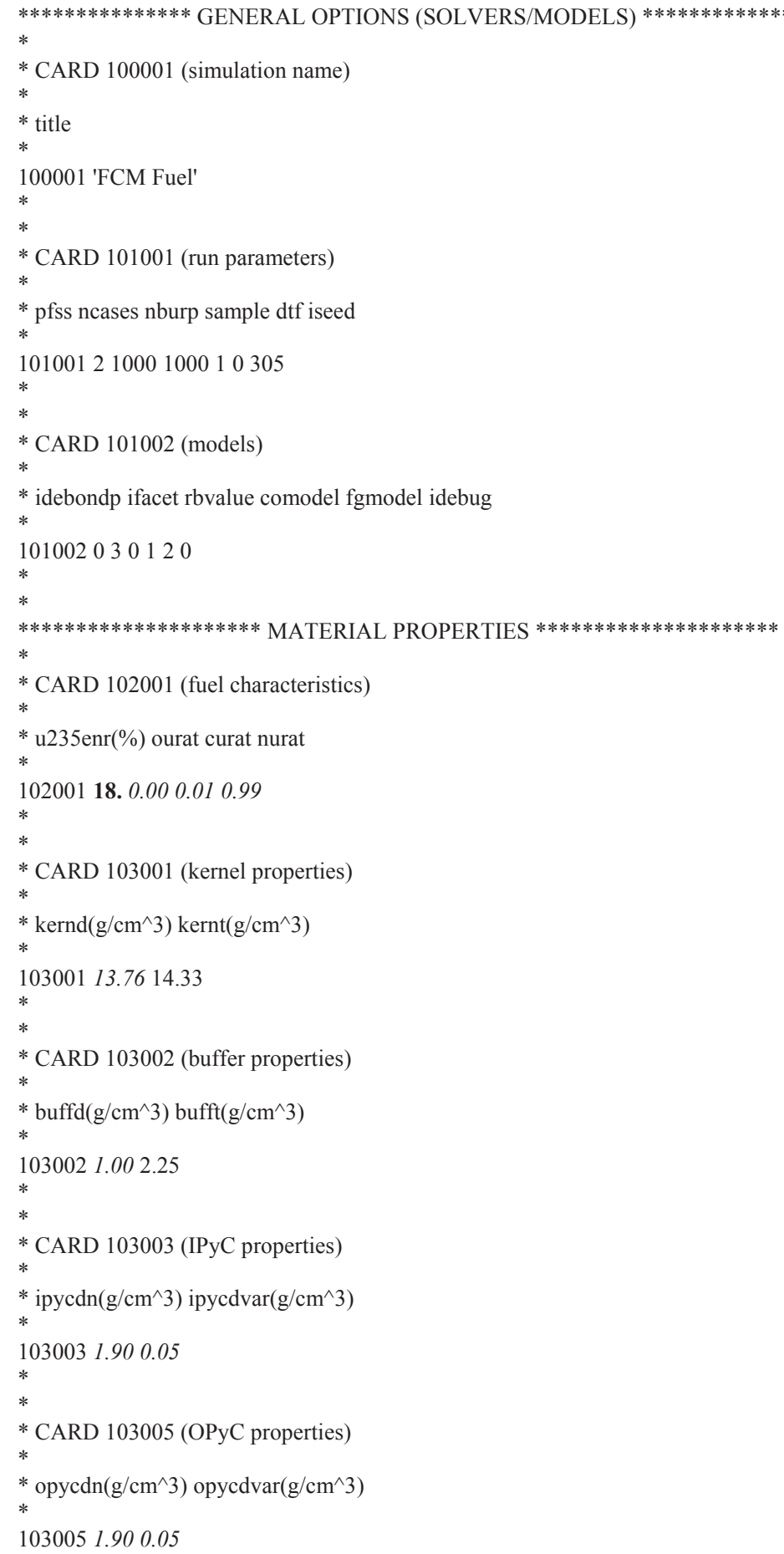




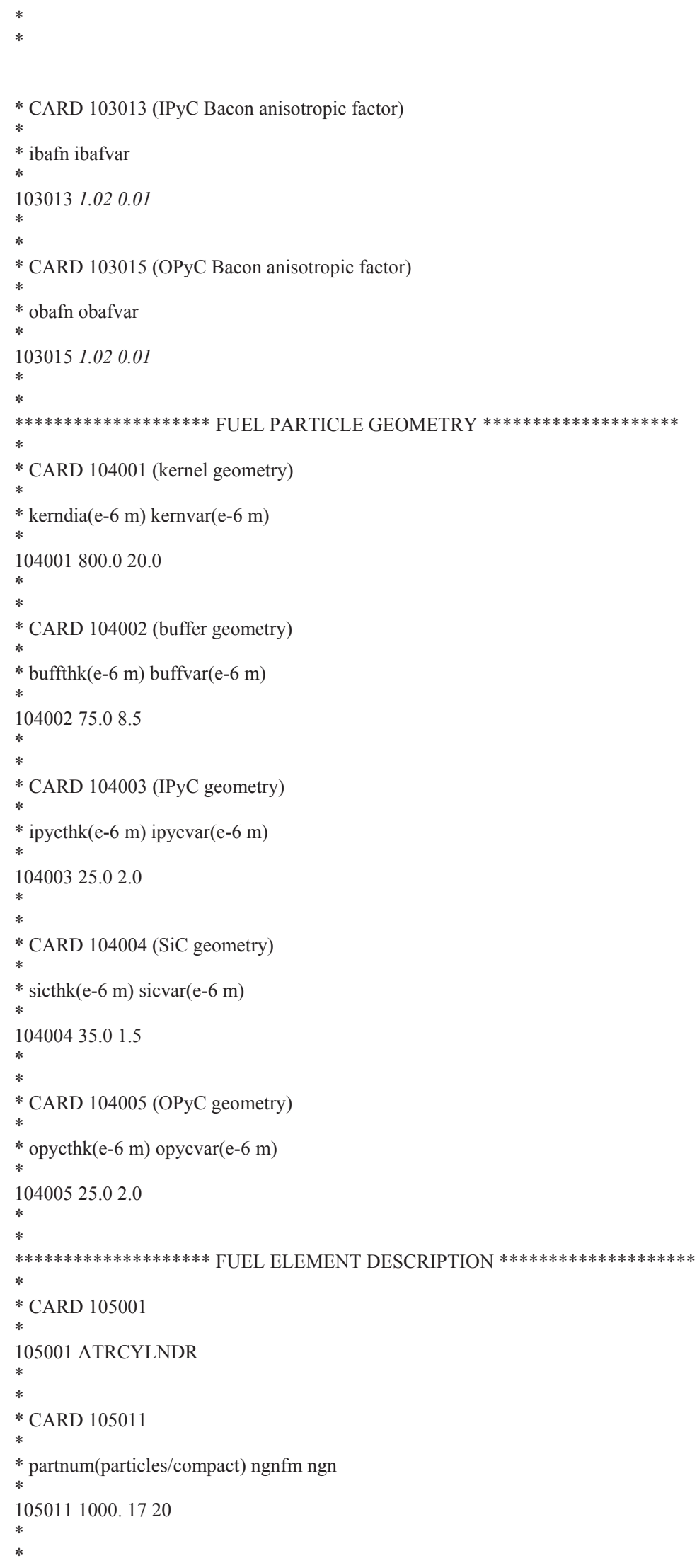




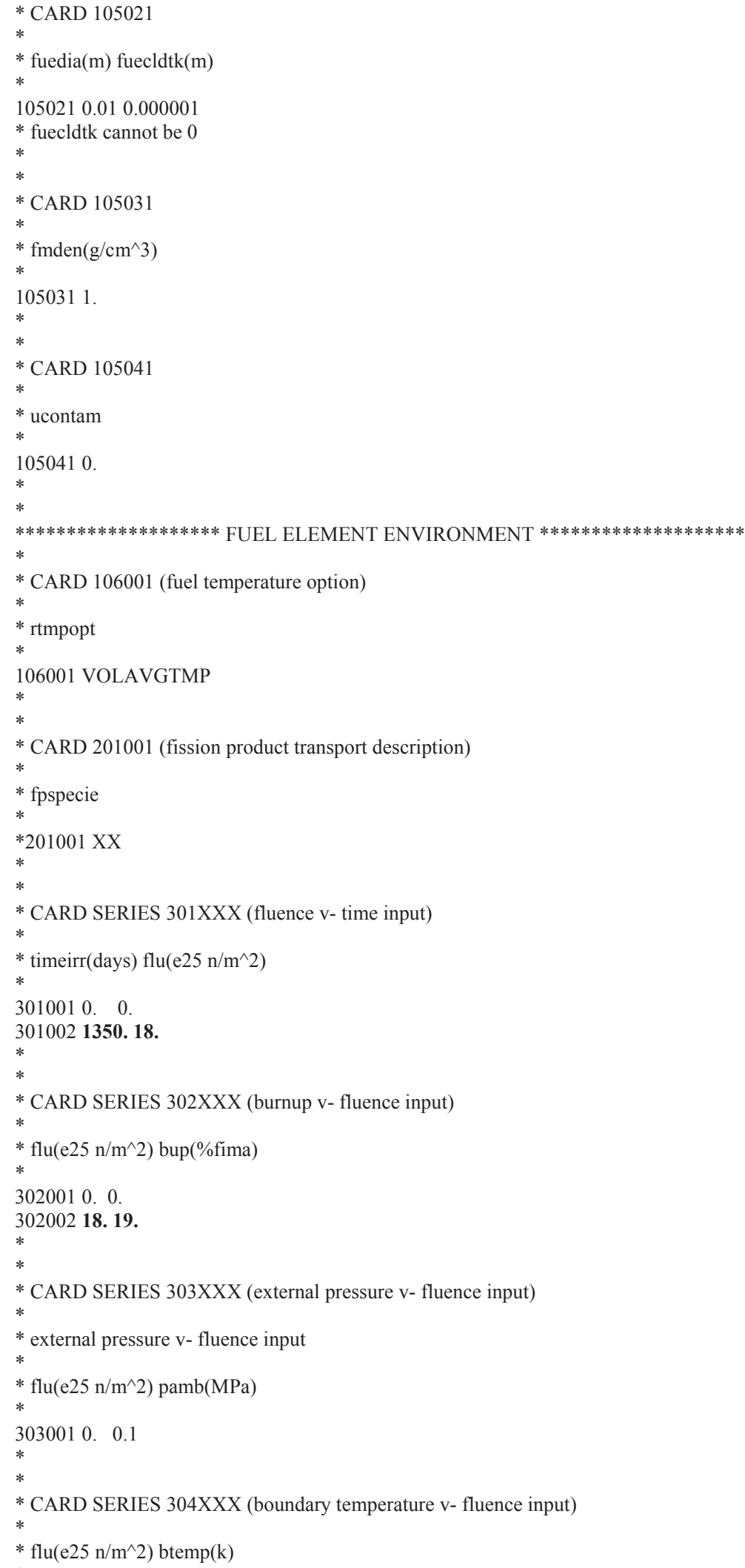


3040010.850.

304002 18. 850 .

*

* CARD SERIES 306XXX (time heatup starts and irradiation ends)

* thus(days)

3060011350.

$*$

************** CORRELATION PARAMETERS AND COEFFICIENTS $* * * * * * * * * * * * *$

$*$

* $\quad \operatorname{sigcr0}(\mathrm{MPa})$ umc(MPa)

$401001 \quad 965.776 \quad 125.300$

* c1c c2c

$401005 \quad 3.593629 \mathrm{E}-02 \quad 1.594342 \mathrm{E}-03$

$401006 \quad 2.035771 \mathrm{E}-02-6.034598 \mathrm{E}-04$

$401007 \quad 1.206647 \mathrm{E}-01 \quad 3.781575 \mathrm{E}-02$

*

* $\quad \operatorname{siga0}(\mathrm{MPa}) \quad$ um( $(\mathrm{MPa}) \operatorname{delum}(\mathrm{MPa})$ aration aratvar

$\begin{array}{llllll}402001 & 950.089 & 358.400 & 264.230 & 1.040 & 0.020\end{array}$

* cla c2a d1a d2a

$402005 \quad 4.674180 \mathrm{E}-03 \quad 1.396723 \mathrm{E}-04 \quad 2.315959 \mathrm{E}-03 \quad 1.456402 \mathrm{E}-04$

$402006 \quad-2.401991 \mathrm{E}-03 \quad-2.057850 \mathrm{E}-05 \quad-2.265337 \mathrm{E}-03 \quad-4.101545 \mathrm{E}-05$

$402007 \quad 5.150608 \mathrm{E}-03 \quad 1.000054 \mathrm{E}-04 \quad 3.378512 \mathrm{E}-03 \quad 9.477511 \mathrm{E}-05$

$402013 \quad-2.232118 \mathrm{E}-01 \quad 9.765533 \mathrm{E}+00 \quad 4.957797 \mathrm{E}-01 \quad 9.934803 \mathrm{E}+00$

* 